NBER WORKING PAPER SERIES

\title{
THE CHALLENGES OF UNIVERSAL HEALTH INSURANCE IN DEVELOPING COUNTRIES: EVIDENCE FROM A LARGE-SCALE RANDOMIZED EXPERIMENT IN INDONESIA
}

\author{
Abhijit Banerjee \\ Amy Finkelstein \\ Rema Hanna \\ Benjamin A. Olken \\ Arianna Ornaghi \\ Sudarno Sumarto \\ Working Paper 26204 \\ http://www.nber.org/papers/w26204
}

\author{
NATIONAL BUREAU OF ECONOMIC RESEARCH \\ 1050 Massachusetts Avenue \\ Cambridge, MA 02138
}

August 2019

We thank our partners at BPJS Kesehatan, Bappenas, TNP2K, and KSP for their support and assistance. In particular, we wish to thank from BPJS Kesehatan Fachmi Idris, Mundiharno, Tono Rustiano, Dwi Martiningsih, Andi Afdal, Citra Jaya, Togar Siallagan, Tati Haryati Denawati, Atmiroseva, Muh. Syahrul, Golda Kurniawati, Jaffarus Sodiq, Norrista Ulil, and the many staff at regional BPJS offices who provided assistance; Maliki and Vivi Yulaswati from Bappenas, Jurist Tan from KSP, and Bambang Widianto and Prastuti (Becky) Soewondo from TNP2K. We thank the outstanding JPAL SEA team members for their work on this study, in particular Ignasius Hasim, Masyhur Hilmy, Amri Ilmma, Ivan Mahardika, Lina Marliani, Patrya Pratama, Hector Salazar Salame, Reksa Samudra, Nurul Wakhidah, and Poppy Widyasari. Yuanita Christayanie provided excellent research assistance. We thank SurveyMeter for outstanding data collection and fieldwork, especially Bondan Sikoki and Nasirudin. Funding from the Australian Department of Foreign Affairs and Trade and KOICA is gratefully acknowledged. The views expressed here are those of the authors, and do not necessarily reflect those of the many individuals or organizations acknowledged here, nor those of the National Bureau of Economic Research.

At least one co-author has disclosed a financial relationship of potential relevance for this research. Further information is available online at http://www.nber.org/papers/w26204.ack

NBER working papers are circulated for discussion and comment purposes. They have not been peer-reviewed or been subject to the review by the NBER Board of Directors that accompanies official NBER publications.

(C) 2019 by Abhijit Banerjee, Amy Finkelstein, Rema Hanna, Benjamin A. Olken, Arianna Ornaghi, and Sudarno Sumarto. All rights reserved. Short sections of text, not to exceed two paragraphs, may be quoted without explicit permission provided that full credit, including (C) notice, is given to the source. 
The Challenges of Universal Health Insurance in Developing Countries: Evidence from a Large-scale Randomized Experiment in Indonesia

Abhijit Banerjee, Amy Finkelstein, Rema Hanna, Benjamin A. Olken, Arianna Ornaghi, and Sudarno Sumarto

NBER Working Paper No. 26204

August 2019

JEL No. I13,O15

\section{ABSTRACT}

To assess ways to achieve widespread health insurance coverage with financial solvency in developing countries, we designed a randomized experiment involving almost 6,000 households in Indonesia who are subject to a nationally mandated government health insurance program. We assessed several interventions that simple theory and prior evidence suggest could increase coverage and reduce adverse selection: substantial temporary price subsidies (which had to be activated within a limited time window and lasted for only a year), assisted registration, and information. Both temporary subsidies and assisted registration increased initial enrollment. Temporary subsidies attracted lower-cost enrollees, in part by eliminating the practice observed in the no subsidy group of strategically timing coverage for a few months during health emergencies. As a result, while subsidies were in effect, they increased coverage more than eightfold, at no higher unit cost; even after the subsidies ended, coverage remained twice as high, again at no higher unit cost. However, the most intensive (and effective) intervention - assisted registration and a full one-year subsidy - resulted in only a 30 percent initial enrollment rate, underscoring the challenges to achieving widespread coverage.

Abhijit Banerjee

Department of Economics, E52-540

MIT

50 Memorial Drive

Cambridge, MA 02142

and NBER

banerjee@mit.edu

Amy Finkelstein

Department of Economics, E52-442

MIT

50 Memorial Drive

Cambridge, MA 02142

and NBER

afink@mit.edu

Rema Hanna

Kennedy School of Government

Harvard University

79 JFK Street

Cambridge, MA 02138

and NBER

Rema_Hanna@hks.harvard.edu
Benjamin A. Olken

Department of Economics, E52-542

MIT

50 Memorial Drive

Cambridge, MA 02142

and NBER

bolken@mit.edu

Arianna Ornaghi

Department of Economics

University of Warwick

Coventry, CV4 7AL

United Kingdom

a.ornaghi@warwick.ac.uk

Sudarno Sumarto

TNP2K

Jl. Kebon Sirih

Jakarta Indonesia

and SMERU

ssumarto@smeru.or.id

A data appendix is available at http://www.nber.org/data-appendix/w26204

A randomized controlled trials registry entry is available at https://www.socialscienceregistry.org/trials/815 


\section{INTRODUCTION}

As developing countries emerge from extreme poverty and enter middle-income status, many aim to expand their government-run social safety net systems (Chetty and Looney 2006). An important part of this process is the creation of universal health insurance policies, which have expanded to many lower- and middleincome countries over the past decade (Lagomarsino et al. 2012). In expanding health insurance, however, emerging countries may face particularly vexing versions of the challenges faced by many developed countries, because of the large informal sector operating outside the tax net (Jensen 2019). Some countries, such as Thailand, have sought a single-payer-like system funded entirely out of tax revenues and supplemented by small co-pays at the time of service (see Gruber, Hendren, and Townsend 2014), which has been shown to improve health, but faces substantial funding challenges. Many other countries, such as Ghana, Kenya, the Philippines and Vietnam - as well as Indonesia, which is the focus of our study - have sought to create a contributory system with an individual mandate to reduce the financial burden on the government. In these systems, the very poor are subsidized by tax revenues, but everyone else is required to pay a premium, collected through a payroll tax for formal sector workers and collected directly from individuals for everyone else.

The challenge with contributory systems, however, is that enforcing the insurance mandate for those who must pay premiums directly is difficult. While the political and administrative challenges of enforcing mandates are not unique to developing countries - for example, the 2010 Obamacare mandate did not achieve universal coverage in the United States (Berchick 2018) - they are particularly difficult for them, again because the majority of their citizens are outside the tax net. This means that the types of penalties for non-compliance used initially in the United States under Obamacare - fines collected through the personal income tax system - are not an option. Since developing countries have shown little appetite for enforcing the few possible remaining sanctions on this population (e.g., denying delinquent households the ability to enroll their kids in school), perhaps rightly, what they are left with is a toothless mandate.

In theory, a toothless mandate can create two related challenges for governments that are trying to achieve universal or near-universal coverage: 1) low program enrollment and 2) adverse selection, where the least healthy are more likely to enroll, raising program costs above the population average (Akerlof 1970; Einav and Finkelstein 2011). In practice, like other nations that have experimented with these policies, Indonesia has experienced both: despite the fact that mandatory, universal health insurance was launched in 2014, the contributory portion of the program, known as JKN Mandiri, had enrolled only 20 percent of the targeted population a year after its introduction, and its claims exceeded premiums by a ratio 
of 6.45 to $1 .^{1}$ These facts motivate the question of whether and how developing country governments can design supplemental policies to mitigate these challenges - to boost national health insurance enrollment, while also reining in the financial costs to the tax-funded government budget - in contexts with mandatory, but weakly enforced, contributory health insurance programs. The aim is not necessarily for the government to break even - it is clear that some subsidies may be needed in order to make sure that there is enough social protection against health shocks - but to limit government spending while insuring as many people as possible.

With this perspective in mind, in 2015, in cooperation with the Indonesian government, we designed a large-scale, multi-arm experiment-involving almost 6,000 households - to assess three interventions that simple economic theory suggested could increase enrollment and reduce adverse selection in the nationally mandated insurance program. First, we examined the role of large, temporary subsidies: we randomized households to receive subsidies of either 50 percent ("half subsidy") or 100 percent ("full subsidy") for the first year of enrollment. To be eligible for the subsidy, households had to enroll within two weeks after they were offered it, akin to governments offering a large, time-limited registration incentive. Second, we examined the role of transaction costs by randomly offering some households at-home assistance with the online registration system, rather than traveling to a far-off insurance office to enroll. Third, we tested for information constraints by randomly advertising three different types of basic insurance information: the financial costs of a health episode and how they relate to insurance prices, the two-week waiting period from enrollment to coverage (so that one could not wait to get sick to sign up), and the fact that insurance coverage is legally mandatory.

To assess the impacts of these interventions, we utilize a number of new data sources. Notably, we have access to the government's administrative insurance data for program enrollees for up to 32 months after the intervention, including detailed data on registration, premiums paid, and all claims made. We first use these data to examine the impact of the interventions on enrollment, which we define as completing the initial registration process. However, as the decision to stay enrolled is a dynamic one, in which households need to pay a monthly premium, we also examine the impact of the interventions on insurance coverage, which we define as having paid the premium for a given month and thus having insurance coverage in that month. Next, given the extensive and detailed administrative data on claims, we examine questions relating both to adverse selection and to the ultimate government costs per household insured under the various policy treatments. Finally, we supplement these administrative data with a short baseline assessment survey in which we collected data on demographics and self-reported health status prior to the intervention. Among

\footnotetext{
${ }^{1}$ Enrollment rates are from authors' calculation based on official membership numbers and the national sample survey, SUSENAS 2015 (BPS 2015). Claims to premium ratios are from LPEM-UI (2015).
} 
other things, this baseline survey allows us to measure pre-intervention "health status" for all study participants, regardless of whether they subsequently enrolled in the insurance program.

In the context of a toothless mandate, our findings reveal both opportunities and challenges for increasing coverage in contributory health insurance programs in developing countries. On the one hand, we find that temporary subsidies and assisted registration can both increase enrollment. Moreover, temporary subsidies attract a much lower-cost population, enabling substantial increases in coverage at no higher cost per covered unit. This increased coverage persists (albeit at a lower rate) after the subsidies end. On the other hand, even our most intensive (and effective) intervention - assisted registration and a full one-year subsidy - resulted in only a 30 percent initial enrollment rate; this was a substantial increase relative to the status quo enrollment rate of 8 percent, but still a far cry from universal coverage. Our analysis reveals specific obstacles to achieving widespread coverage stemming from limited state capacity to facilitate enrollment and to prevent strategic short-term coverage.

Our study explicitly builds on the literature on participation in public health insurance systemsand in social protection programs, more broadly — not only by testing the impact of these individual policy tools on enrollment, but also by testing the relative magnitudes of relieving different participation constraints against one another in a common real-world context. ${ }^{2}$ Theory suggests that the constraints that we examine - reduced prices, reduced transaction costs and increased information — could each increase enrollment in various types of public programs, including health insurance. And, in fact, the empirical evidence is consistent with this theory: the findings from both developed and developing settings indicate that subsidies (e.g. Thornton et al. (2010); Asuming (2013); Fischer et al. 2018; Finkelstein, Hendren and Shepard 2019), reductions in transaction costs (e.g. Alatas et al. 2016; Bettinger et al. 2012; Dupas et al 2016), and information (Gupta 2017; Bhargava and Manoli 2015) all have the potential to increase participation in a variety of social insurance programs, motivating our experimental design. Importantly, our extensive high-frequency administrative data allow us to build upon this literature, as we can precisely study whether these different types of interventions have persistent results over time, as individuals make dynamic, and possibly strategic, decisions over insurance coverage each month. ${ }^{3}$ This is particularly

\footnotetext{
${ }^{2}$ This study, in particular, is related to Thornton et al. (2010), which examine the impact of whether informal workers, recruited through a health insurance registration booth in the market, are randomized to receive a subsidy for contributory insurance through Nicaragua's social security system offices or through a microfinance organization, which could potentially have been more convenient for the informal workers. Their study finds impacts of subsidies on enrollment, and therefore on utilization, but does not study how the treatments affect the degree to which the market is adversely or advantageously selected, as we do here.

${ }^{3}$ In the developing world, there is little known about the longer-run impacts of improving health insurance take-up, as well as selection, through interventions. One notable exception is Asuming et al. (2018), which uses survey data to assess the impact of one-time subsidies on enrollment and subsequent health behaviors in Ghana, three years post-
} 
important for the temporary subsidies, if "experience" with the health care system leads households to increase their perceived value of insurance and stay covered after the subsidies expire. ${ }^{4}$

We then go further to examine not only the impacts on overall enrollment, but also whether these interventions affect the type of individual who enrolls - as well as remains enrolled - and thus whether it is possible to increase enrollment of low-utilization individuals enough to reduce the per-participant cost of insurance. In the standard textbook models in which individuals differ only in their risk type, the interventions that we test could all potentially mitigate adverse selection, since the marginal enrollees will be lower-cost than the average enrollees (e.g. Akerlof 1970). However, in the presence of multiple dimensions of heterogeneity, the impact of these interventions on adverse selection is theoretically ambiguous (Einav and Finkelstein 2011); and indeed, existing evidence from health insurance studies indicates that while such interventions can ameliorate adverse selection (e.g. Fischer et al. 2018; Finkelsten, Hendren, and Shepard 2019), they can also, in different contexts, exacerbate it (Asuming et al. 2018; Handel 2013). It is therefore an empirical question whether varying the different insurance constraints, holding constant the setting, leads to a different type of enrollment, and in particular one that makes a meaningful difference in terms of participant costs.

More specifically, our three interventions produce three distinct sets of findings. First, we find that the one-year full subsidies significantly boosted enrollment and improved selection, leading to more people insured at the same cost to the government, even after the subsidies expired. Those offered the full subsidy were 20.9 percentage points (almost seven times) more likely to enroll than were those in the no-subsidy group during the active subsidy period. This increase was not driven simply by households who would have purchased insurance anyway ("harvesting"), but rather represents a real net increase in enrollment. While some of these households did not elect to pay premiums upon the end of the one-year subsidy, many did; as a result, in the year after the subsidy ended, insurance coverage in the full-subsidy group remained over twice as high as coverage in the no-subsidy group — consistent with the idea of health insurance as an experience good.

intervention. Our high-frequency, administrative data allow us to further unpack the dynamics of selection and show how differential retention affects our understanding of these health insurance markets. The only related paper that we know that explores these issues does so in a developed country setting, studying California's Affordable Care Act (Diamond et al. 2018).

${ }^{4}$ Delavallade (2017) provides evidence that a related "experience" effect could be important, by showing that randomly providing households with a free preventive health visit increased their hypothetical willingness to pay for insurance in a subsequent survey. 
Despite the fact that more households enrolled under the full-subsidy treatment, the net cost to the government per covered person - i.e., the difference between revenues from premiums and payments to providers, and hence the amount that would need to be covered from the general government budget -- was similar with and without the full subsidy. Remarkably, this was true even in the first year, when the subsidy was active and hence when the full-subsidy group brought in essentially no revenue. This is because the subsidies brought in substantially lower-cost enrollees: relative to enrollees in the no-subsidy group, those in the full-subsidy treatment reported better health at baseline and had fewer claims (and notably, fewer claims for chronic conditions) during their first year of enrollment. This cost difference may also, in part, reflect strategic timing decisions by the no-subsidy group, rather than fixed health differences alone: in fact, the no-subsidy enrollees submitted more claims than did full-subsidy enrollees in the first three months after enrollment, after which the difference between the two groups attenuates. Also, many enrollees in the no-subsidy group subsequently dropped coverage - i.e., stopped paying premiums - after a few months. Such strategic enrollment timing was less of an option for full-subsidy enrollees because the subsidy offer was time-limited and, once enrolled, they stayed covered for the full first year. In the second year, once the full-subsidy group had to begin paying premiums, the full-subsidy group brought in slightly more revenue to the government since more people were enrolled (due to the experience effect highlighted above), but the value of their claims appears similar to the value of those in the control group.

In contrast, the half-subsidy offer was less effective than the full subsidy. The half-subsidy treatment enrolled fewer people than the full subsidy - the treatment effect was about half that of the full subsidy, and did not appear large enough to generate an experience effect in the second year. Nor do we observe a large selection effect on claims. Taken together, in the first year, despite bringing in more revenue than the full subsidy, the half-subsidy treatment led to fewer households covered than the full subsidy at a higher per-enrollee cost.

Second, while the subsidy treatments highlight that the monetary cost of insurance is a barrier to enrollment, monetary cost alone cannot fully explain limited enrollment. Instead, we find that hassle costs also appear to be a real barrier to participation, and one that we were not able to fully solve. Reducing hassles by assisting with internet-based registration increased enrollment by 3.5 percentage points (41 percent). But, importantly, many more people attempted to enroll than were actually able to do so: in fact, nearly as many people attempted to enroll in the assisted internet-based registration as in the full-subsidy group. Combined, when offered both a full subsidy and assisted internet registration, nearly 60 percent of households tried to enroll, but only about half were successfully able to do so. Households' efforts were substantially muted by technical and administrative challenges with the government's online enrollment system. While also reminiscent of the issues with Healthcare.gov in the United States, this particular 
challenge stemmed from a problem common to many developing countries: Indonesia's underlying state civil registry, i.e., the data on who is in each family, is often inaccurate (Sumner and Kusumaningrum 2014), and since whole families must be enrolled at once (to help mitigate adverse selection), these problems in the civil registry meant that people needed to visit an office to fix errors and sign up correctly. Since imperfect civil registries are common throughout the developing world (Mikkelsen et al. 2015), these types of challenges are likely to be encountered in other contexts as well.

We also find that those who enrolled in the assisted internet registration group stopped paying premiums at a faster rate than those who enrolled under the status quo registration, perhaps reflecting that those who selected in under this treatment might also be those who are easily discouraged by the hassle costs involved in making payments each month. Not surprisingly, given their high dropout rate, we do not observe any differences in the claims of the assisted registration group as compared to the status quo registration group.

Third, none of the information treatments affected enrollment into the system. The fact that our various information treatments had no impact suggests that lack of information may not be a key barrier, although we cannot rule this out definitively. However, it does suggest that while information and nudge campaigns are often an attractive policy option given their low cost (Thaler and Sunstein 2009), this does not seem to be the primary constraint in this context.

Taken together, the most important take-away from our results is that large, temporary subsidies can work. A common concern with offering a "free" trial period is that individuals may become used to receiving insurance without paying, thus decreasing payments in the long-run. We find the opposite: temporary registration incentives, featuring limited periods of free coverage before requiring premiums to be paid, actually increase coverage and premiums paid in the subsequent year while reducing adverse selection. This may be because many households in developing countries lack experience with insurance (Aacharya et al. 2012), suggesting an important role for registration drives featuring temporary "free subsidy" periods to give people experience with insurance as part of campaigns to increase enrollment.

Despite the fact that we find that these large temporary subsidies can substantially boost enrollment, particularly among lower-cost enrollees, we did not find a silver bullet that would lead to universal (or even close to universal) enrollment: even the most intensive intervention - assisted registration plus the free insurance for a year - only resulted in a 30 percent initial enrollment rate. While this is substantially higher than the status quo initial enrollment rate of 8 percent, it is still a far cry from universal enrollment; moreover, many newly enrolled households further dropped coverage over time. 
Nevertheless, our findings offer important insights for how to further improve these types of programs on the margin. First, as already mentioned, a trial period of free insurance had significant positive effects - increasing enrollment rates while substantially mitigating adverse selection - at no additional cost to the government. Second, our results suggest that the dynamics of coverage decisions can exacerbate adverse selection. Thus, a key administrative challenge lies not just in enforcing the enrollment mandate which was the premise for our interventions - but also in designing insurance regulations to prevent the strategic timing of gaining and dropping coverage. Finally, as the assisted internet registration treatment demonstrated, without substantial long-run investments in overall administration and infrastructure (e.g., improved identification systems and better internet connections), there will continue to be substantial hassles that prevent universal insurance coverage.

The remainder of the paper is organized as follows. Section II presents the setting, the experimental design, and the data used in the analysis. Section III presents the enrollment effects of the intervention as well as its impacts on coverage over time. Section IV presents the selection effects, and discusses their implications for government costs. The last section concludes.

\section{SETTING, EXPERIMENTAL DESIGN AND DATA}

\section{A. Setting: the JKN Mandiri program}

In January 2014, the Government of Indonesia launched Jaminan Kesehatan Nasional (JKN), a national, contributory health insurance program aimed at providing universal coverage by 2019. JKN comprises different sub-programs based on income and employment status. Non-poor informal workers, which represent 30 percent of the country, are covered through a sub-program called JKN Mandiri. Under JKN Mandiri, households must complete an initial registration process and then subsequently pay their monthly premiums. ${ }^{5}$ While insurance enrollment is legally mandatory, the mandate is hard to enforce in practice, and there are currently no penalties assessed on households who do not enroll.

Households may register for JKN Mandiri at any time of the year, either in person at the Badan Penyelenggara Jaminan Sosial - Kesehatan (Social Security Administration for Health, or BPJS) office or through the social security administration website. Households are required to register all nuclear family

\footnotetext{
${ }^{5}$ Those below the poverty line (about the bottom 40 percent) receive fully subsidized insurance. Formal workers are covered jointly by employees and employers, and their contributions are withheld by the tax system.
} 
members (e.g., father, mother, and children), as listed on their official Family Card (Karta Keluarga), which is maintained in the civil registry by another ministry (Department of Home Affairs).

The per-person monthly premium for basic coverage (known as Class III) is IDR 25,500 ( $\$ 2$ ), corresponding to 3.5 percent of average monthly total expenditures for eligible households. ${ }^{6}$ The premium that a household would pay to have JKN coverage for a year is lower than the reported yearly out-of-pocket health expenditures for 12 percent of all non-poor informal households without health insurance, but this percentage reaches 66 percent for households who had an inpatient episode in the last year, in which case the median "savings" from having health insurance are large (IDR 231,341 per month). ${ }^{7}$

The premium can be paid at any social security administration office, ATM, or equipped convenience store. Paying the premium by the $10^{\text {th }}$ of a given month ensures coverage for that calendar month. If no payment is made, coverage is deactivated after a one-month grace period. For coverage to reactivate at a later date, the household must pay arrears, which are capped at a maximum of 6 months. ${ }^{8}$ After the program's introduction, the government became concerned that individuals might only enroll in JKN when they had a health emergency. To limit this, in September 2015, the government introduced a two-week waiting period after enrollment, only after which households could submit an insurance claim.

An active membership provides coverage for healthcare costs incurred at public or affiliated clinics and hospitals with no co-pays, although specific procedures (e.g., cosmetic surgery, infertility treatments, orthodontics, etc.) are excluded. Primary care clinics are reimbursed under capitation based on the total number of practitioners, the ratio of practitioners to beneficiaries, and operating hours. Hospitals are reimbursed by case following a tariff system called INA-CBG (Indonesia Case Base Groups), in which amounts are determined jointly by primary diagnosis and severity of the case.

\section{B. Sample}

We carried out this project in two large Indonesian cities: Kota Medan in North Sumatra and Kota Bandung in West Java. We focused on an urban setting to abstract from supply-side issues that are likely to depress

\footnotetext{
${ }^{6}$ There are three different classes that cover the same medical procedures, but offer different types of accommodations should an inpatient procedure be required. The per-person monthly premium during the period of the study was IDR $42,500(\sim 3)$ for class II ( $3-5$ beds per room) and IDR 59,500 ( $\sim 4.5)$ for class I ( $2-3$ beds per room). Class III (more than 5 beds) is the most common insurance among our population of interest, with 72 percent of households in the control group enrolling in Class III insurance.

${ }^{7}$ For each household, we compute what would have been the yearly JKN premium based on household size and compare with the yearly out-of-pocket expenditures reported in the survey using SUSENAS 2015 data (BPS 2015).

${ }^{8}$ If no inpatient claims are submitted within 45 days from re-activation, there are no additional fees. Otherwise, the household has to pay a penalty equal to 2.5 percent of the treatment cost times the number of inactive months, up to a maximum of 12 months or IDR 30 million.
} 
demand in rural areas. We chose Medan and Bandung because a significant fraction of their population was uninsured. ${ }^{9}$ Moreover, selecting cities both on- and off-Java helps ensure representativeness of Indonesia's heterogeneity in culture and institutions (Dearden and Ravallion 1988).

Working with the government, we implemented the interventions in two sub-districts in Medan in February 2015 and in eight sub-districts in Bandung in November and December 2015. The sub-districts were selected from among those with the highest concentration of non-poor informal workers; within those sub-districts, we randomly selected neighborhoods for the study. ${ }^{10}$ To identify JKN-eligible households within the sampled areas, we targeted uninsured, informal workers by administering a rapid eligibility survey to all listed households. We excluded households that already had at least one member covered by health insurance and those that were officially below the poverty line (and thus qualified for free insurance). Of the 52,584 listed households, 14.5 percent $(7,629)$ satisfied the target population criteria.

When we matched our survey data with the government's administrative data, we discovered that some households were already covered by health insurance, even if they reported that they were not. This was mostly an issue for the city of Medan, where the local government had recently expanded the set of poor households who qualified for free insurance, but had not yet communicated this to the newly insured. Since households with at least one insured member were not eligible for the study, we excluded those already enrolled, resulting in a sample of 5,996 households.

\section{Experimental design}

Upon identifying an eligible household, we administered a short baseline survey (see below for details), at the end of which the household was randomly assigned to three fully-crossed treatment arms affecting the insurance price, the hassle cost of registration and the information available (see Figure 1).

\section{Temporary Subsidy Treatments}

Households were randomly selected to be in one of three groups: a control group, a full-subsidy group covering the premiums for all family members for one year, and a half-subsidy group covering half of a

\footnotetext{
${ }^{9}$ Other large cities, such as Jakarta, Surabaya and Makassar, introduced free local health insurance programs covering a large fraction of the population. Neither Bandung nor Medan had local programs of this type during the study period.

${ }^{10}$ Using the 2010 Census, we chose sub-districts with a high fraction of non-poor informal workers. We excluded subdistricts with universities, large factories, or malls to avoid areas with a high concentration of temporary residents. We then randomly selected twelve kelurahan (urban municipal units) in the two sub-districts in Medan (out of 16 possible kelurahan) and four kelurahan in each sub-district in Bandung (out of 41 possible kelurahan). Within each kelurahan, we randomly selected the neighborhoods (rukun warga, also known as RW) to enumerate.
} 
family's premiums for a year. ${ }^{11}$ After the offer, the subsidy was valid for up to two weeks in Bandung and two weeks in Medan; to be conservative and ensure sure we capture all households who enroll during the subsidy period even accounting for data lags, our definition of households enrolled during the subsidy period includes all households that enrolled within eight weeks of the offer date.

For logistical reasons, we could not pay half of each person's premium. Instead, we implemented the half subsidy through a "buy-one-get-one-free" scheme in which we paid the full premiums for half the family members for one year, and the household was then required to pay for the other half. ${ }^{12}$ Households chose which family members were subsidized. In theory, the government regulated that all immediate household members be registered, so subsidizing half of the household members was roughly equivalent to providing a 50 percent discount. The subsidy receipt for the subsidized members was conditional on payment for the non-subsidized members for the first month, but unconditional thereafter in practice. Households in the full subsidy period were not required to make any payments during the subsidy period.

\section{Assisted Internet Registration treatment}

Registering for JKN Mandiri usually requires traveling to the social security administration office in the district capital. To reduce the hassle costs of registration, we offered half of the study households the possibility of completing the registration process online at home with the assistance of the study enumerator. The enumerators had internet-enabled laptops that they used to access the official social security website. They then assisted the household with gathering the correct documentation, taking pictures and filling in all of the forms on the website. Upon successful registration, the enumerators provided information on payment procedures. If households wanted to think more about their options, wanted to enroll but needed time to assemble the documentation, or had technical registration problems, the enumerators returned within a few days to continue the enrollment process.

\section{Information treatments}

All study households received basic information about the insurance service coverage, the premiums, the procedure for registration, etc. For randomly selected households in each city, we provided additional types of information to test whether various forms of knowledge constrained enrollment.

\footnotetext{
${ }^{11}$ In Medan, households with a positive subsidy offer were randomized to receive a one-week deadline, a two-week deadline, or the ability to choose either a one- or two-week deadline to enroll using the subsidy. In Bandung, we additionally offered a fourth subsidy sub-treatment in which households that enrolled, but did not submit an inpatient claim within a 12-month period were reimbursed 50 percent of the premiums that they had paid. Since these subtreatments only took place in one of the two cities, we exclude them from the main analysis, but we discuss these findings below and show the results in the accompanying appendix.

${ }^{12}$ If a family had an odd number of members, we randomly assigned the household to receive a subsidy for $(y+1) / 2$ or $(y-1) / 2$ members with equal probability. If there was only one member, the member received a full subsidy.
} 
In Medan, we randomly assigned a group of households to receive additional information on the financial costs of a health episode ("extra information treatment"). Using a script and an accompanying booklet, we detailed the average out-of-pocket expenditures for Indonesia's most common chronic health conditions, as well as the cost of having a heart attack.

In Bandung, all households received basic insurance information, as well as a discussion of the outof-pocket expenditures associated with accessing care. However, based on discussions with the government, we then randomly assigned households to the following two treatments: 1) a "waiting period" treatment, in which we informed households about the new two-week waiting period between enrollment and the start of coverage, and 2) a "mandate penalties" treatment, in which we reminded households that enrollment is mandatory, and that there was a possibility that the government would soon introduce regulations requiring proof of insurance to be able to renew government documents, such as passport, driver's license, etc.

\section{Randomization design and timing}

Figure 1 shows the experimental design for the cities of Medan and Bandung separately. ${ }^{13}$ Figure 2 provides the experimental timeline. The study occurred in February 2015 in Medan and in November and December 2015 in Bandung. Subsidies were administered for twelve months after the offer for those who enrolled within two weeks of the offer.

\section{E. Data and Variable Definitions}

We compiled two new datasets for this project. First, we conducted a short baseline survey in conjunction with an independent and established survey firm (SurveyMeter). We administered the baseline survey immediately following the listing questionnaire to determine eligibility. The baseline survey collected information on the demographic characteristics of family members, self-reported health and previous health care utilization, and existing knowledge of the program. ${ }^{14}$ Self-reported health was measured on a fourpoint scale from 1 (unhealthy) to 4 (very healthy); we analyze average self-reported health across household

\footnotetext{
${ }^{13}$ The number of households differs in each treatment for two reasons. First, while in Medan we maximized power to detect differences in enrollment, in Bandung we maximized power to detect differences in claims conditional on takeup. Since we expected greater take-up with a larger subsidy, we randomized more households into groups with smaller subsidy amounts. Second, a coding error meant that while the overall treatment probabilities were as assigned, some combinations of treatments were more likely to be randomly assigned to households than others (this coding error was corrected partway through the Bandung experiment). We include in the analysis a dummy for whether the old or new randomization was used, and reweight observations to obtain the intended cross-randomization weights so that each main treatment group has the same mix of each crossed additional treatment.

${ }^{14}$ To minimize priming, the questions related to knowledge of the program were asked after the information on health status. The consent form only mentioned SurveyMeter and Indonesia's National Development Planning Agency (Bappenas), the other partner in the study, but not the social security administration or JKN.
} 
members. The survey was identical in Bandung and Medan, with the one exception being that we added questions on income and employment in Bandung.

Second, we use uniquely detailed government administrative data from February 2015 to August 2018 to measure enrollment outcomes, coverage, and health care utilization. ${ }^{15}$ We track all participants for 32 months after the baseline survey. We matched the study participants to the administrative data using individuals' unique national identification number (Nomor Induk Kependudukan or NIK). ${ }^{16}$

We define enrollment to be the household's successful completion of the registration process for the national insurance program. Since a household may enroll but not actually pay any premiums, we then also define coverage in a given month to mean that the enrolled household's premiums were paid that month. We use the administrative data on registration date to measure enrollment. We use the administrative premium payment data, which report the date and value of each payment, to measure coverage.

To measure health care utilization, we analyze administrative data on all claims that are covered by JKN in both hospitals and clinics. The hospital claim data report start and end date, diagnosis, reimbursement value, and facility where the claim was made. ${ }^{17}$ We are able to distinguish between outpatient and inpatient hospital claims. In contrast, all clinic claims are for outpatient procedures. The clinic claims data report similar information to the hospital claims data, except that - due to capitation claim values are not available. In addition to overall claims, we report two other types of information. First, since claims data are often noisy, we also examine the number of days until the first claim was submitted. Second, we use the diagnoses to code whether the claim was for a chronic condition. ${ }^{18}$

\footnotetext{
${ }^{15}$ The administrative data quality is good and has been improving over time, but some inconsistencies still arise. To ensure that we identify the correct individuals, we exclude matches when the year of birth reported in the baseline and that reported in the administrative database differ by more one year. When the same NIK links to two different membership numbers, we consider both observations as a match. When two different NIKs link to the same membership number, we exclude the observation. When enrollment date or membership type changes in subsequent extracts, we retain the information as reported in the first extract in which the individual appears.

${ }^{16}$ About 23 percent of the individuals surveyed did not have a NIK at baseline and cannot be matched to the administrative data. We show in Column 1 of Appendix Table 1 that the probability that a household reports the NIK of at least one of its members is not differential across treatment. Given that a NIK is a requirement of enrollment, those without a NIK are likely not enrolled in JKN.

${ }^{17} \mathrm{~A}$ claim corresponds to an outpatient or inpatient event. Each event is associated with a series of diagnoses. The hospital is reimbursed for the amount that corresponds to the primary diagnosis according to the INA-CBG tariff. All exams and treatment needed for an event get reimbursed under the same claim.

${ }^{18}$ We build our chronic classification from the Chronic Condition Indicator for the International Classification of Diseases from the Healthcare Cost and Utilization Project. This database provides information on whether diagnoses included in the ICD-10-CM: 2018 can be classified as chronic conditions. We link conditions in the ICD-10-CM: 2018 to conditions in the ICD-10: 2008 - the classification system followed by BPJS - using the first three digits of the diagnosis code. This is the lowest classification that straightforwardly corresponds across the two systems. We consider a diagnosis as chronic if it belongs to a three-digit code group with more than 75 percent chronic diagnoses.
} 


\section{F. Balance}

Appendix Table 1 provides a check on the randomization by regressing various household characteristics measured in the baseline survey on treatment dummies. Only 6 out of the 54 coefficients are significantly different from zero at the 10 percent level, in line with what we would expect by chance.

\section{IMPACTS ON ENROLLMENT AND ON SUBSEQUENT COVERAGE}

\section{A. Enrollment}

Table 1 and Table 2 examine the impacts of the various treatments on enrollment - i.e., successfully completing the registration process. We measure enrollment over the first year after the intervention date i.e., the date the baseline survey occurred. We estimate the following regression:

$y_{i}=\beta_{0}+\beta_{1} H_{A L F S U B S I D Y_{i}}+\beta_{2}$ FULL SUBSIDY $_{i}+\beta_{3} \operatorname{INTERNET}_{i}+\operatorname{INFO}_{i}^{\prime} \beta_{4}+X_{i}^{\prime} \delta+\varepsilon_{i}$

where HALF SUBSIDY, FULL SUBSIDY $Y_{i}$ and INTERNET $T_{i}$ are dummy variables equal to 1 if household $i$ was randomly assigned to the respective treatment, and $I N F O_{i}$ is a vector of dummies equal to 1 if household $i$ was randomly assigned to a particular information intervention. $X_{i}$ is a matrix of householdlevel controls that includes dummy variables for the assignment to the other treatments (see footnote 11), a dummy for the randomization procedure (see footnote 13) and a dummy variable for city of residence. Regressions are weighted to reflect the desired cross-treatment randomization design (see footnote 13). Given the household-level randomization, we report robust standard errors. ${ }^{19}$

Table 1 presents present the coefficients for HALF SUBSIDY $Y_{i}$ FULL SUBSIDY $Y_{i}$, and INTERNET from equation (1), as well as the $p$-values from a test that the half and the full subsidy have the same treatment effect (i.e., $\beta_{1}=\beta_{2}$ ) and from a test that the full subsidy and the assisted internet registration have the same effect (i.e., $\beta_{1}=\beta_{3}$ ). Column 1 examines whether the household was enrolled within the 12 months while the subsidies were active. In Column 2, we examine whether households initiated the enrollment process, regardless of whether they successfully enrolled. ${ }^{20}$ In Column 3 , we examine

\footnotetext{
${ }^{19}$ Note that to facilitate comparisons, we separate out interventions reported in tables. Nevertheless, the full set of indicator variables is always included.

${ }^{20}$ For households assigned to the assisted internet registration treatment, we set attempted enrollment equal to 1 if they stated that they wanted to enroll during the visits. For households assigned to follow the status quo registration procedures, we recorded whether they showed up to the office, regardless of whether they were successful in enrolling. Since only households with a voucher had to contact the study assistant at the social security office, we do not know whether households assigned to the no-subsidy group attempted to enroll if they were not ultimately successful in enrolling. For these households, attempted enrollment is set equal to actual enrollment, a choice justified by the fact that the failure rate for households assigned to the status quo registration in the subsidy treatments was negligible.
} 
enrollment within eight weeks of offer date (i.e., when the subsidy offer was valid plus some margin for error). ${ }^{21}$ In Column 4, we consider enrollment after the subsidy offer expired, but throughout the subsidy period (up to 1 year from the offer date).

We focus first on Panel A. Column 1 shows that the subsidies substantially increased the probability of enrollment during the following 12 months after the offer date, while assisted registration had a positive but smaller impact. Only about 9 percent of the no-subsidy group enrolled within the 12-month period. Relative to this, offering the full subsidy increased enrollment by 18.6 percentage points (216 percent), while offering the half subsidy increased enrollment by 10 percentage points ( 116 percent). In contrast, the assisted internet registration treatment only increased enrollment by 3.5 percentage points ( 40 percent $){ }^{22}$

The enrollment measure by itself masks the fact that many more households, particularly those in the assisted internet treatment, attempted to enroll than were successful. Assisted internet registration led to a 23.8 percentage point increase in attempted enrollment during the first eight weeks (column 2), but only a 4.3 percentage point increase in successful enrollment during that period (column 3 ). This indicates that less than one-fifth of the households induced by the registration assistance to attempt enrollment were actually successful in doing so. The most common reason for unsuccessful enrollment was an inaccurate Family Card, the official identification document (see Appendix Table 3). In order to combat adverse selection, the government required that households enroll all nuclear family members as listed in this document, which was pulled automatically from the digital records held by the Home Affairs Ministry. This turned out to be problematic if the family composition had changed, but the document was not updated. In practice, updating the card is challenging - it cannot be updated online, and instead requires at least one trip to a Home Affairs-linked administrative office, and can often incur delays and other additional costs. During in-person enrollment, social security administration officials use discretion to overrule the system for cause (e.g., if households had documentation that the Home Affairs record was inaccurate), but the lack of flexibility in the online system made web enrollment nearly impossible for many.

The evidence in Column 3 of impacts on enrollment within the first eight weeks also raises the question of whether the interventions merely shifted forward in time an enrollment decision that would have occurred anyway (so-called "harvesting"). This seems particularly plausible given that both the offer of registration assistance and the subsidy offers were time-limited. Therefore, Column 4 shows the probability of enrolling after the subsidy offer expired - specifically, after eight weeks post-offer but within

${ }^{21}$ For all groups (including the control group), the offer date is that of the baseline survey. For subsidy group households, we consider households who have a signup date in the administrative data within eight weeks from the offer date as having enrolled using the subsidy to allow for potential delays in the data.

${ }^{22}$ Appendix Tables $2 \mathrm{a}$ and $2 \mathrm{~b}$ replicate Table 1 , but disaggregate the data by city. Overall, subsidies had similar effects on actual enrollment in the two cities. 
one year of the offer date. The results indicate that the subsidy interventions reduced the probability of enrolling in this period, but the decline is significantly smaller than the increase due to the subsidies in the initial period (shown in Column 3). Thus, harvesting is relatively small, accounting for no more than about 10 percent of the total additional enrollment we observed in the first eight weeks.

\section{B. Barriers to universal enrollment}

The results in Table 1, Panel A, show enrollment impacts from the intervention, but also indicate that even with a full subsidy for a year, most people do not enroll. One explanation is that the hassle costs of enrollment discussed above are large enough to provide a barrier, even when the insurance has no monetary costs. To investigate this, Panel B of Table 1 shows estimates from an enhanced version of equation (1) that also includes a full set of interactions between the (cross-randomized) subsidy treatments and the assisted intervention treatment. Column 1 shows that even with a full subsidy and assisted internet registration, enrollment only reached 30 percent. Column 2 shows that less than 60 percent of households even tried to enroll when offered both free insurance for the year and assistance with registration. This suggests that while hassle costs provide a significant barrier — even when the insurance is free- they do not fully explain why people do not enroll.

We therefore explored other potential barriers to enrollment. Table 2 examines the role of potential information barriers. We report the results separately by city because we tested different information treatments in different cities, providing detailed information on heart attack costs in Medan (Panel A) and about the nature of insurance (i.e., that enrollment is mandatory and that households must enroll in advance of a health shock) in Bandung (Panel B). We find no statistically significant effect of any of these information treatments. We can rule out effect sizes respectively bigger than 8.5 percentage points (information on heart attack costs), 2.5 percentage points (information on mandates) and 3.2 percentage points (information on waiting period). ${ }^{23}$

\section{Coverage Dynamics}

Insurance coverage is not a one-time decision. After the initial decision to enroll that we examined in Table 1 , households must decide whether to continue to pay their monthly premiums to remain covered at any given point in time. We now turn to the administrative data on premium payments to examine these monthly payment decisions.

\footnotetext{
${ }^{23}$ In Medan, we also experimentally tested whether individuals would want the offer, but procrastinate on it. Specifically, households with a positive subsidy offer were cross-randomized into different deadlines: one-week, twoweek, or the possibility to choose between a one- and a two-week deadline to enroll using the subsidy. As shown in Appendix Table 4, this treatment also had effects that were indistinguishable from zero.
} 
Figure 3 plots coverage by month since the offer date, by subsidy group. Coverage for a household is defined as the premium having been paid in full for all its members that month. Payment may be made either independently by the household or by the study; thus all households in the full subsidy group who successfully enroll are covered for twelve months.

In the no-subsidy group, coverage slowly increased over time from 0.61 percent in the first month of the experiment to 6.66 percent almost two years later. However, many enrollees quickly dropped coverage; one-quarter of enrolled control group households had stopped paying their premiums three months post-enrollment, and nearly half of the enrollees in the no-subsidy group had stopped paying their premiums a year post-enrollment (Appendix Figure 1). The steady increase in coverage for the no-subsidy group in Figure 3 implies that the rate of new enrollment was large enough so that net coverage rates continued to increase despite the dropout effect. ${ }^{24}$

Interestingly, the different subsidy groups exhibited quite different levels and patterns of coverage, both before and after the subsidies expired. In the full-subsidy group, roughly 25 percent of those offered the full subsidy enrolled in the first two months after the offer, and their coverage mechanically remained constant during the first year, when the subsidies were active. ${ }^{25}$ While the full-subsidy group also had a high dropout rate after the subsidy ends (at about month 13-14), their coverage levels continued to remain higher than the no-subsidy group, even at 20 months after the offer date. ${ }^{26}$ The fact that those brought in with the temporary full subsidy stayed enrolled in the second year suggests a strong "experience effect," i.e., that these individuals may not have understood the benefits of insurance until they experienced it. This implies that temporary subsidies can help boost enrollment past their expiration date, and may be an important tool in boosting insurance coverage in low-enrollment settings.

As one may expect from theory, results for the half-subsidy group are somewhere between the nosubsidy and full-subsidy results. Their coverage rate in the first year was higher than the no-subsidy group, but far below the full-subsidy group. They also experienced a drop in coverage when the subsidy ended, and while their coverage level was roughly flat in the second year, the no-subsidy group slowly caught up to them. By the 20 -month mark, their coverage rates appear similar.

\footnotetext{
${ }^{24}$ The steady increase in enrollment of the no-subsidy group throughout the study period is in line with the number of enrollees going from approximately 10 million in January 2015 to more than 15 million in January 2016.

${ }^{25}$ The slight increase in coverage shown in Figure 3 for the full-subsidy group during months 4-12 comes from the fact that a small number of households in this group enrolled after the subsidy period was over.

${ }^{26}$ Appendix Figure 1 shows the coverage rate for the sample of those who enrolled in the first year, by month of enrollment. One can see a continuous decline in payments for those in the no- and half-subsidy groups. In contrast, there is a sharp decline for those in the full-subsidy group at month 13, the exact time when households had to start paying premiums.
} 
Table 3 summarizes the coverage patterns in Figure $3 .{ }^{27}$ In Column 1, we report the percentage of households that enrolled and had coverage for at least one month in the first year after the offer. Columns 2 and 3 decompose those with coverage in Column 1 into those who no longer had coverage by month 15 ("the dropouts") and those who did ("the stayers"); Column 4 provides the $p$-value of the difference in the dropout vs. stayer shares. Column 5 reports the percentage who had coverage in month 15, after the subsidies ended, relative to all households in the sample; note that the interpretation in this column differs from Column 3 since we do not condition on the household having enrolled within 1 year of the offer date. Column 6 reports $p$-values for tests of whether coverage rates were the same during the subsidy period (Column 1) and at 15 months (Column 5). Finally, Columns 7 and 8 report the same information for month 20 since offer date. In the final 3 rows of the table, we provide the $p$-values for tests of whether the fulland half-subsidy coverage rates each differ from the no-subsidy coverage rates $\left(\beta_{1}=0\right.$ and $\left.\beta_{2}=0\right)$, as well as whether the assisted-registration coverage rates differs from the status quo registration $\left(\beta_{3}=0\right)$. Appendix Table 5 provides the underlying regression estimates for the $\mathrm{p}$-values reported in this table.

Table 3 quantifies the magnitude of several important patterns observed in Figure 3. First, the fullsubsidy group retained substantially higher coverage than the no-subsidy group, even after the subsidies were over. Those offered the full subsidy were 4.6 percentage points $(86$ percent; $p$-value $<0.001)$ more likely than the no-subsidy group to have coverage at month 15 (column 5), and 3.9 percentage points (58 percent; $p$-value 0.001 ) more likely than the no-subsidy group to have coverage at month 20 . This again suggests that health insurance is an experience good - those who were covered for free for a limited time were much more likely to pay for coverage afterwards than those who were never offered free insurance.

Second, despite the experience effect, we still document statistically significant declines in coverage in the subsidy treatments. As shown in Figure 3, we observe significantly higher coverage rates for both the full-subsidy and half-subsidy group in the first year, when the subsidy was still active (Column 1). By 20 months, after all subsidies had expired, coverage had fallen substantially and the coverage rates at 20 months were no longer statistically distinguishable between the half-subsidy and no-subsidy group. Even for the full-subsidy group, where we document the persistence of coverage above, comparing Columns 1 and 7 shows that about 61 percent of those who ever had coverage in the first year had dropped coverage by month 20 (10.6 percent in month 20 covered compared to 27.7 percent covered at some point in the first year; $p$-value $<0.001)$. These results suggest that while temporary subsidies can lead to

\footnotetext{
${ }^{27}$ We report means in each treatment group in this and subsequent tables to facilitate comparisons both across time and across treatment groups. The means for each cell are calculated using the weights described in footnote 13, so that each treatment group shown has the same (weighted) combination of sub-treatments; that is, half subsidy has the same weighted mix of status quo vs. assisted internet registration as full subsidy, and so on.
} 
substantial increases in coverage even after the subsidies are over, only about 40 percent of those subsidized continue to retain coverage.

Finally, it is important to note that while the assisted-registration group saw a slight increase in coverage initially (Column 1), their coverage rate quickly converged to that of the control group. This suggests that some of the households brought into the insurance system by reducing hassles may have been particularly sensitive to the hassles of paying each month, leading to the increased dropout rate. One possible reason is that while the assisted internet registration made registration easier, it did not resolve the hassles of paying one's premium, which still needed to be done at an office, ATM, or convenience store.

\section{Selection Impacts and its Implications on Government Costs}

\section{A. Impacts on Selection}

Subsidies are a textbook response to concerns about adverse selection, since in standard models they will induce lower-cost individuals to enroll. To examine the types of people who enroll under different intervention arms, we draw on two sources of data: self-reported health from the baseline survey, and administrative claims data among those who enrolled. While these two measures capture different objects - namely, health and healthcare usage - perhaps not surprisingly, enrollees with better self-reported health indeed tend to have fewer claims (see Appendix Table 6).

Table 4 shows the results. ${ }^{28}$ It shows various measures of health and healthcare use for those who enrolled and had coverage for at least one month during the first year (i.e., as measured in column 1 of Table 3). Column 1 indicates that the marginal household who received coverage in response to the subsidies had a higher level of self-reported health at baseline than enrollees in the no-subsidy group. Those enrolling with the subsidies had an average self-reported health score that is about 4.5 percent higher than that of no-subsidy enrollees, with both subsidy treatment effects significant at the 5 percent level. The effects of assisted internet registration were smaller, but in the same direction, and statistically significant at the 10 percent level. ${ }^{29}$

The remaining columns of Table 4 examine healthcare usage of households who enrolled and had coverage for at least one month during the first year. We examine all claims for the 12 months after the enrollment date; by examining a fixed number of months since enrollment date regardless of when

\footnotetext{
${ }^{28}$ The regressions that calculate these $p$-values are provided in Appendix Table 7.

${ }^{29}$ Appendix Table 8 shows that the results holds also if self-reported health is measured in as the self-reported health of the least healthy family member. In addition, households who enrolled under the full subsidy treatment were also less likely to have a family member above 60 .
} 
households enrolled, we can abstract from the feature that temporary subsidies may drive households to enroll earlier in a calendar year thus mechanically affecting length of insurance coverage. We focus on three main indicators: whether the household had any claim (column 2), the total number of visits made (column 6), and the total value of claims paid (column 10). We then subdivide claims into outpatient, inpatient, and chronic. We also examine the number of days to first claim, which can provide greater precision than the value of claims, which tend to have a large right tail (Aron-Dine et al. 2015).

Consistent with the results on self-reported health in column 1, the claims analysis in the remaining columns also indicates that those who enrolled under the full subsidy were healthier and lower-cost. Households in the full-subsidy group were less likely to submit claims. For example, in the no-subsidy group, 62 percent had any claim compared to 48 percent in the full-subsidy group (column 2; $p$-value 0.040). Those in the full-subsidy group were also less likely to have had a claim for a chronic, ongoing condition: 27 percentage points for the no-subsidy group compared to 17 percentage points for the full-subsidy group (column 5; $p$-value 0.082 ). Results for the half-subsidy group are mostly qualitatively similar to the fullsubsidy group, but smaller in magnitude and never statistically significantly different from the no-subsidy group. The same is true of the results for the assisted internet registration group.

In addition to having fewer overall claims, claims in the full subsidy group were less likely to be "large claims" that suggest a substantial health emergency. This is shown in Figure 4, which reports the probability distribution function of the value of inpatient claims submitted within twelve months since enrollment, by treatment status, for those who enrolled within a year since offer date and paid for at least one month. The distribution of values of claims for the full-subsidy group is markedly left-shifted relative to the no-subsidy group. Again, the same is true - although less pronounced - in comparing the half-subsidy and no-subsidy groups. The differences across groups are statistically significant according to a Kolmogorov-Smirnov test for equality of distribution functions ( $p=0.012$ for the test of equality between the distribution of the half-subsidy and no-subsidy groups and $p=0.001$ for the test of equality between the distribution of the full-subsidy and no-subsidy groups). In short, when they use the health care system, those whose coverage was heavily subsidized have less expensive health incidents.

On net, the fact that the full-subsidy group had fewer claims, and that these claims were small, results in substantial reductions in claims expenditures from the insurer. In particular, the full-subsidy group had average claims that were 40 percent lower in value than those in the no-subsidy group (column 10 of Table 4; $p$-value 0.095 ) and on average waits 30 percent longer before submitting their first claim (column 11 ; $p$-value 0.006 ).

\section{B. Dynamics and Selection}


An important question is whether the fact that households can time enrollment and dropout decisions exacerbates adverse selection. We investigate both a) whether households in the no-subsidy group, who do not face a time limited enrollment period, are more likely to time enrollment to when they are likely to have a claim, and b) how those who choose to retain coverage differ from those who drop.

Figure 5 begins by plotting the number of claims by month since enrollment, separately by subsidy treatment groups among households who enrolled within one year since offer and had coverage for at least one month over that period, along with 95 percent confidence intervals. Those who enrolled without the subsidy appear to have submitted more claims in the first few months upon enrollment than did the households in the full-subsidy group, but over time this difference became less stark and, by the end of the period, they displayed similar patterns in number of claims. Households in the half-subsidy group also submitted more claims than households in the full-subsidy group, and even submitted claims for a higher value than the no-subsidy group in a handful of months. ${ }^{30}$ Combined with the payments findings in the previous section (i.e., Figure 3), this suggests that no-subsidy households may have had large claims once they enrolled, but then stopped paying premiums (i.e., dropped coverage). In contrast, the subsidy groups brought in healthier people, who kept paying premiums longer in the first year while the subsidies were active (see Figure 3), and had smaller claims throughout the year (Figure 5).

Table 5 investigates differential selection in terms of who retained coverage. For each treatment, we divide those who enrolled in the first year into "dropouts" - those who did not still have coverage in month 15 - and "stayers" - those who did. The coverage rates of these two groups are shown in Table 3. Several results are worth highlighting. In the full-subsidy group, those who retained coverage had higher baseline self-reported health than those who did not (column 1; $p$-value 0.068 ). On the other hand, the stayers were also more likely to have had claims (column $2 ; p$-value 0.005 ) and to have had more visits (column 6; $p$-value 0.002). These were particularly likely to be outpatient claims/visits and those for chronic conditions, rather than inpatient claims. The half-subsidy group showed a similar pattern of claims. ${ }^{31}$ The pattern for the no-subsidy group is more ambiguous, with the dropouts more likely to have had an inpatient claim, but having had fewer overall visits.

\footnotetext{
${ }^{30}$ Appendix Table 9 formally confirms this result. In the first 3 months that the households were enrolled in insurance (Panel A), full-subsidy households were less likely to submit inpatient or outpatient claims, had lower overall claims than the control group, and their inpatient claims were on average for lower values. The coefficient on the half-subsidy group is generally negative, but the difference is not always statistically significant. Months four through twelve after enrollment (Panel B) show that, over time, the difference disappears: all of the treatment groups display a very similar pattern of claims, although the coefficient for the full-subsidy group is overall still negative.

${ }^{31}$ Appendix Table 10 presents the equivalent results broken down by the assisted internet registration treatment, and finds a similar pattern: stayers were more likely to have had claims, particularly inpatient and outpatient claims. Appendix Table 11 presents the regressions from which we calculate the $p$-value of the difference in means reported in Table 5 and in Appendix Table 10.
} 
The results from the subsidy treatments continue to suggest an experience effect: those who stayed were those who made use of the system, even for smaller outpatient or chronic conditions. They also raise the possibility that allowing relatively small payments from a plan (as opposed to a high-deductible plan that only covers catastrophic expenses) may be important for continuing to entice healthy people to remain covered.

\section{Implications for government costs}

The selection patterns indicate that the subsidies brought in healthier enrollees, while the coverage dynamics indicate that not only were no-subsidy enrollees sicker and higher-cost, but that they strategically timed enrollment to coincide with major health expenditures, and were quicker to drop coverage (i.e., stop paying premiums) after a few months. In Table 6, we examine the implications of these results for the net costs to the government. The results indicate that the subsidies covered more households at similar cost per covered household. ${ }^{32}$

Table 6 shows net revenues with and without accounting for capitation payments by month, which can be decomposed into revenues from premiums and government expenditures as a result of claims. ${ }^{33}$ Revenues are defined as premiums paid by enrollees. ${ }^{34}$ Claims expenditures are defined as the value of claims paid. In columns 2 to 5 , we focus on revenues and expenditures per household-month covered; this provides us with estimates of the additional revenue and expenditure for each additional household covered in a given month. As an alternative way of presenting the same results, columns 6 through 9 report the results for all households in the sample regardless of whether they enrolled in the insurance, thus providing us the total revenues and costs of offering the policy; these estimates reflect the corresponding cells in columns 2 through 5 , scaled by the number of covered households in that group.

Panel A explores the impacts on government net costs during the period when the subsidy was in effect. While the subsidy was active, on net the government lost around IDR 125,000 ( \$9) per household-

\footnotetext{
${ }^{32}$ Appendix Table 12 presents equivalent results split by assisted internet registration vs. status quo registration, and finds no substantial differences in net costs to the government. Appendix Table 13 reports the regressions that correspond to the $p$-values reported in Table 6 and Appendix Table 12.

${ }^{33}$ Capitation payments depend on the number of enrollees that declare the facility as their primary provider, the total number of practitioners, the ratio of practitioners to beneficiaries, and operating hours, and range between IDR 3,0006,000 per enrollee for puskesmas and IDR 8,000-10,000 for clinics. Given that approximately 80 percent of $J K N$ Mandiri enrollees declare puskesmas and 20 percent declare clinics as their primary health facility, for these calculations we assume capitation payments to be IDR 6,800 per enrollee per month. Capitation payments are only paid to healthcare facilities in months in which the household paid the premium.

${ }^{34}$ They should therefore be mechanically zero for the full-subsidy group while the subsidy is in effect, but are not literally zero since a few households in this group enrolled after the time period the subsidy offer was in effect and therefore had to pay premiums.
} 
month covered in the no-subsidy group (Column 5, Panel A). By comparison, over this same period, on net the government lost only about IDR 50,000 ( \$3.50) per household-month covered in the full-subsidy group (Column 5, Panel A). In other words, the net cost to the government per covered household-month in the subsidy group was no higher than in the no-subsidy group ( $p$-value $=0.19$ ), even taking into account that the government received essentially no revenue from the subsidy group. This is because the decline in average claims between the full-subsidy and no-subsidy groups (Column 3: decline of IDR 152,000 per covered household-month; $p$-value 0.026 ) was even larger than the forgone revenue from not collecting premiums (Column 2: decline of IDR 71,000 per covered household-month; $p$-value $<0.001$ ). ${ }^{35}$ As a result, the full subsidy resulted in over eight times more covered household-months (Column 1), at no higher cost to the government per household-month covered (Column 5).

Of course, there are more people covered, so this policy does entail an increase in the total amount spent by the government in total. Looking over the entire sample (i.e., not conditioning on enrollment), Column 9 indicates that in the no-subsidy group the government cost was IDR 3,000 ( $\sim \$ 0.20)$ per eligible household per month, while with the full-subsidy the government cost was IDR 6,000 ( $\sim 0.40)$ per eligible household per month.

Panel B explores what happened in the year after the subsidies were withdrawn. As shown in Table 3 , there was some persistent increase in coverage in the full-subsidy group. However Table 5 shows that despite being healthier initially, households in the full-subsidy group that retained coverage (i.e., paid premiums) after the subsidy ended were more likely to have had a claim during the first year than those who dropped coverage after the subsidy ended. As a result, those who retained coverage had similar average claims after the subsidy ended to those in the no-subsidy group. On net, Table 6, Panel B (Column 5) indicates that government costs were not statistically different per covered household-month for the nosubsidy group and the full-subsidy group in the period after the subsidy ended, though the point estimates suggest that that the government lost about half as much per covered household-month in the full subsidy group compared to the no-subsidy group (IDR 47,000 in net government costs per covered householdmonth in the full-subsidy group; IDR 102,000 in net government costs per covered household-month in the no-subsidy group). Thus, in the year after the temporary full subsidy ended, we estimate that twice as many household-months were covered (Panel B, Column 1), at no higher cost per covered household-month (Panel B, Column 5). Looking over the entire sample (i.e., not conditioning on enrollment), Column 9

\footnotetext{
${ }^{35}$ For household-months covered in the half-subsidy group, the net losses are similar to those in the no-subsidy group (about IDR 160,000 per covered household-month); again, the fact that net revenue losses are only slightly larger for the half-subsidy group than for the no-subsidy group - despite mechanically lower revenues - reflects the healthier composition of the half-subsidy pool.
} 
indicates virtually identical government expenditures (about IDR 5,000 per person) in the year after the subsidies end for the full-subsidy group compared to the no-subsidy group.

Putting this all together, one can calculate the bottom-line implications for the government for offering a temporary full subsidy to a given population. In the year the subsidy was in effect, the government doubled its net budgetary contribution for this population (from IDR 3,000 to IDR 6,000 per person offered). During that year, coverage expanded dramatically - from 6.3 percent of the population to 27.7 percent of the population. In the subsequent year, the bottom line for the government was the same - about IDR 5,000 per person in the population - regardless of treatment. But the full-subsidy group had, on net, 58 percent more people covered, with the same total government expenditure. This is very far from universal coverage - the full-subsidy group had 10.6 percent covered at 20 months after the project started, compared to 6.7 percent in the no-subsidy group - but it represents meaningfully more people covered with no additional ongoing cost to the government.

\section{CONCLUSION}

As incomes have risen in emerging economies, there has been a growing move to increase coverage of social insurance programs. However, insurance mandates can be difficult to enforce. We examine the impact of temporary insurance subsidies - which must be taken up within a month of offer and only last a year - reduced hassle costs, and information provision on insurance coverage in a mandated insurance setting. We find that offering a full, but temporary, subsidy was effective at increasing enrollment and helped attract healthier enrollees. Because of the healthier selection and also the strategic dynamic adjustment of coverage and claims in the no-subsidy group - the no-subsidy group timed its enrollment to coincide with high expenditures and quickly dropped coverage a few months later - the net cost to the government per covered household-month of the full subsidy is no higher, even despite the cost of the subsidies. Importantly, subsidies induced higher enrollment even after they expired, in line with health insurance being an experience good. As a result, after the subsidy period was over, the government was able to cover substantially more people at a roughly similar net cost.

But, at the same time, our findings also highlight challenges that governments face when aiming to achieving universal health coverage through a contributory system. While both subsidies and assisted enrollment increased enrollment rates, even the most aggressive interventions - a full subsidy for a year and internet-assisted enrollment, only led to 30 percent enrollment - a substantial increase from the 8 percent enrollment in the status quo group, but a far cry from universal enrollment. Some of this reflects administrative challenges: almost 60 percent of households in the full subsidy, internet assisted registration 
treatment tried to enroll - double the amount who actually did so. This underscores how weak social insurance infrastructure (in this case, the underlying social registry) can create obstacles to universal enrollment and suggests that long-run solutions to universal coverage are only feasible through strengthening overall administrative structures. 


\section{References}

Acharya, Arnab, Sukumar Vellakkal, Fiona Taylor, Edoardo Masset, Ambika Satija, Margart Burke, and Shah Ebrahim. 2012. "Impact of National Health Insurance for the Poor and the Informal Sector in Low-and Middle-Income Countries." Systematic Review, The EPPI-Centre .

Akerlof, George. 1970. "The Market for Lemons: Quality Uncertainty and the Market Mechanism." Quarterly Journal of Economics 84 (3):488-500.

Alatas, Vivi, Abhijit Banerjee, Rema Hanna, Benjamin A. Olken, Ririn Purnamasari, and Matthew Wai-Poi. 2016. "Self-targeting: Evidence from a Field Experiment in Indonesia." Journal of Political Economy 124 (2):371-427.

Aron-Dine, Aviva, Mark Cullen, Liran Einav, and Amy Finkelstein. 2015. "Moral Hazard in Health Insurance: Do Dynamic Incentives Matter?" Review of Economics and Statistics 97 (4):725-741.

Asuming, Patrick O. 2013. "Getting the Poor to Enroll in Health Insurance, and its effects on their health: Evidence from a Field Experiment in Ghana." Working Paper.

Asuming, Patrick Opoku, Hyuncheol Bryant Kim, and Armand Sim. 2019. "Long-Run Consequences of Health Insurance Promotion when Mandates are not Enforceable: Evidence from a Field Experiment in Ghana." Working Paper.

Badan Pusat Statistik. 2015. "Survei Sosial Ekonomi Nasional Maret (KOR)."

Berchick, Edward R, Emily Hood, and Jessica C Barnett. 2018. "Health Insurance Coverage in the United States: 2017." Current Population Reports, P60-264, US Government Printing Office, Washington, $D C$.

Bettinger, Eric P, Bridget Terry Long, Philip Oreopoulos, and Lisa Sanbonmatsu. 2012. "The Role of Application Assistance and Information in College Decisions: Results from the H\&R Block FAFSA Experiment." The Quarterly Journal of Economics 127 (3):1205-1242.

Bhargava, Saurabh and Dayanand Manoli. 2015. "Psychological Frictions and the Incomplete Take-up of Social Benefits: Evidence from an IRS Field Experiment." American Economic Review 105 (11):3489-3529.

Capuno, Joseph J, Aleli D Kraft, Stella Quimbo, Carlos R Tan, and Adam Wagstaff. 2016. “Effects of Price, Information, and Transactions Cost Interventions to Raise Voluntary Enrollment in a Social Health Insurance Scheme: a Randomized Experiment in the Philippines." Health Economics 25 (6):650-662.

Chetty, Raj and Adam Looney. 2006. "Consumption Smoothing and the Welfare Consequences of Social Insurance in Developing Economies." Journal of Public Economics 90 (12):2351-2356. 
Dearden, Lorraine and Martin Ravallion. 1988. "Social Security in a Moral Economy: An Empirical Analysis for Java." The Review of Economics and Statistics :36-44.

Delavallade, Clara. 2017. "Quality Health Care and Willingness to Pay for Health Insurance Retention: A Randomized Experiment in Kolkata Slums." Health Economics 26 (5):619-638.

Diamond, Rebecca, Michael J Dickstein, Timothy McQuade, and Petra Persson. 2018. “Take-Up, Drop-Out, and Spending in ACA Marketplaces." NBER Working Paper No. 24668.

Einav, Liran and Amy Finkelstein. 2011. "Selection in Insurance Markets: Theory and Empirics in Pictures." Journal of Economic Perspectives 25 (1):115-38.

Finkelstein, Amy, Nathaniel Hendren, and Mark Shepard. 2019. "Subsidizing Health Insurance for Low-Income Adults: Evidence from Massachusetts." American Economic Review .

Fischer, Torben, Markus Frölich, and Andreas Landmann. 2018. "Adverse Selection in LowIncome Health Insurance Markets: Evidence from a RCT in Pakistan.” IZA DP No. 11751.

Fitzpatrick, Anne and Rebecca Thornton. 2018. "The Effects of Health Insurance within Families: Experimental Evidence from Nicaragua." World Bank Economic Review .

Gerard, François and Gustavo Gonzaga. 2018. "Informal Labor and the Efficiency Cost of Social Programs: Evidence from the Brazilian Unemployment Insurance Program." NBER Working Paper No. 22608.

Gruber, Jonathan, Nathaniel Hendren, and Robert M Townsend. 2014. "The Great Equalizer: Health Care Access and Infant Mortality in Thailand." American Economic Journal: Applied Economics $6(1): 91-107$.

Gupta, Sarika. 2017. "Perils of the Paperwork: The Impact of Information and Application Assistanceon Welfare Program Take-Up in India." Working Paper.

Handel, Benjamin R. 2013. "Adverse Selection and Inertia in Health Insurance Markets: When Nudging Hurts." American Economic Review 103 (7):2643-82.

Jensen, Anders. 2019. "Employment Structure and the Rise of the Modern Tax System." NBER Working Paper No. 25502.

Lagomarsino, Gina, Alice Garabrant, Atikah Adyas, Richard Muga, and Nathaniel Otoo. 2012. "Moving Towards Universal Health Coverage: Health Insurance Reforms in Nine Developing Countries in Africa and Asia." The Lancet 380 (9845):933-943.

Mikkelsen, Lene, David E Phillips, Carla AbouZahr, Philip W Setel, Don De Savigny, Rafael Lozano, and Alan D Lopez. 2015. "A Global Assessment of Civil Registration and Vital Statistics Systems: Monitoring Data Quality and Progress." The Lancet 386 (10001):1395-1406. 
Sumner, Cate and Santi Kusumaningrum. 2014. AIPJ Baseline Study on Legal Identity: Indonesia's Missing Millions. Australia Indonesia Partnership for Justice.

Thaler, Richard H and Cass R Sunstein. 2009. Nudge: Improving Decisions about Health, Wealth, and Happiness. Penguin.

Thornton, Rebecca L, Laurel E Hatt, Erica M Field, Mursaleena Islam, Freddy Solís Diaz, and Martha Azucena González. 2010. "Social Security Health Insurance for the Informal Sector in Nicaragua: a Randomized Evaluation." Health Economics 19 (S1):181-206.

Wagstaff, Adam, Ha Thi Hong Nguyen, Huyen Dao, and Sarah Bales. 2016. "Encouraging Health Insurance for the Informal Sector: a Cluster Randomized Experiment in Vietnam." Health Economics 25 (6):663-674. 
Figure 1: Experimental Design

\begin{tabular}{|c|c|c|c|c|c|}
\hline \multirow{2}{*}{} & \multicolumn{9}{|c|}{ Medan } & \multicolumn{2}{c|}{$\begin{array}{c}\text { Subsidy } \\
\end{array}$} \\
\cline { 2 - 6 } & $\begin{array}{c}\text { Standard } \\
\text { information }\end{array}$ & $\begin{array}{c}\text { Extra } \\
\text { information }\end{array}$ & $\begin{array}{c}\text { Standard } \\
\text { information }\end{array}$ & $\begin{array}{c}\text { Extra } \\
\text { information }\end{array}$ & treatment totals \\
\hline No subsidy & 37 & 63 & 134 & 237 & 471 \\
\hline Half subsidy & 171 & 215 & 26 & 97 & 478 \\
\hline Full subsidy & 176 & 54 & 170 & & 497 \\
\hline $\begin{array}{c}\text { Registration } \\
\text { treatment totals }\end{array}$ & 716 & & 730 & \\
\hline
\end{tabular}

\begin{tabular}{|c|c|c|c|c|c|c|}
\hline \multicolumn{7}{|c|}{ Bandung } \\
\hline & & \multicolumn{2}{|c|}{ Status quo } & \multicolumn{2}{|c|}{ Assisted internet registration } & \multirow{2}{*}{$\begin{array}{c}\text { Subsidy } \\
\text { treatment totals }\end{array}$} \\
\hline & & $\begin{array}{c}\text { Standard } \\
\text { information }\end{array}$ & $\begin{array}{c}\text { Mandate } \\
\text { information }\end{array}$ & $\begin{array}{c}\text { Standard } \\
\text { information }\end{array}$ & $\begin{array}{c}\text { Mandate } \\
\text { information }\end{array}$ & \\
\hline \multirow{2}{*}{ No subsidy } & $\begin{array}{c}\text { Standard } \\
\text { information }\end{array}$ & 236 & 307 & 241 & 274 & \multirow{2}{*}{2236} \\
\hline & $\begin{array}{l}\text { Waiting period } \\
\text { information }\end{array}$ & 232 & 300 & 297 & 349 & \\
\hline \multirow{2}{*}{ Half subsidy } & $\begin{array}{c}\text { Standard } \\
\text { information }\end{array}$ & 160 & 153 & 77 & 82 & \multirow{2}{*}{918} \\
\hline & $\begin{array}{l}\text { Waiting period } \\
\text { information }\end{array}$ & 141 & 114 & 100 & 91 & \\
\hline \multirow{2}{*}{ Full subsidy } & $\begin{array}{c}\text { Standard } \\
\text { information }\end{array}$ & 85 & 40 & 62 & 54 & \multirow{2}{*}{478} \\
\hline & $\begin{array}{c}\text { Waiting period } \\
\text { information }\end{array}$ & 63 & 51 & 70 & 53 & \\
\hline \multirow{2}{*}{ Bonus subsidy } & $\begin{array}{c}\text { Standard } \\
\text { information }\end{array}$ & 114 & 86 & 170 & 111 & \multirow{2}{*}{918} \\
\hline & $\begin{array}{c}\text { Waiting period } \\
\text { information }\end{array}$ & 101 & 86 & 131 & 119 & \\
\hline \multicolumn{2}{|c|}{ Registration treatment totals } & \multicolumn{2}{|c|}{2269} & \multicolumn{2}{|c|}{2281} & \\
\hline
\end{tabular}

Note: This figure shows the randomization into each treatment arm, by city. Each cell reports the number of households allocated to the specific treatment cell. 


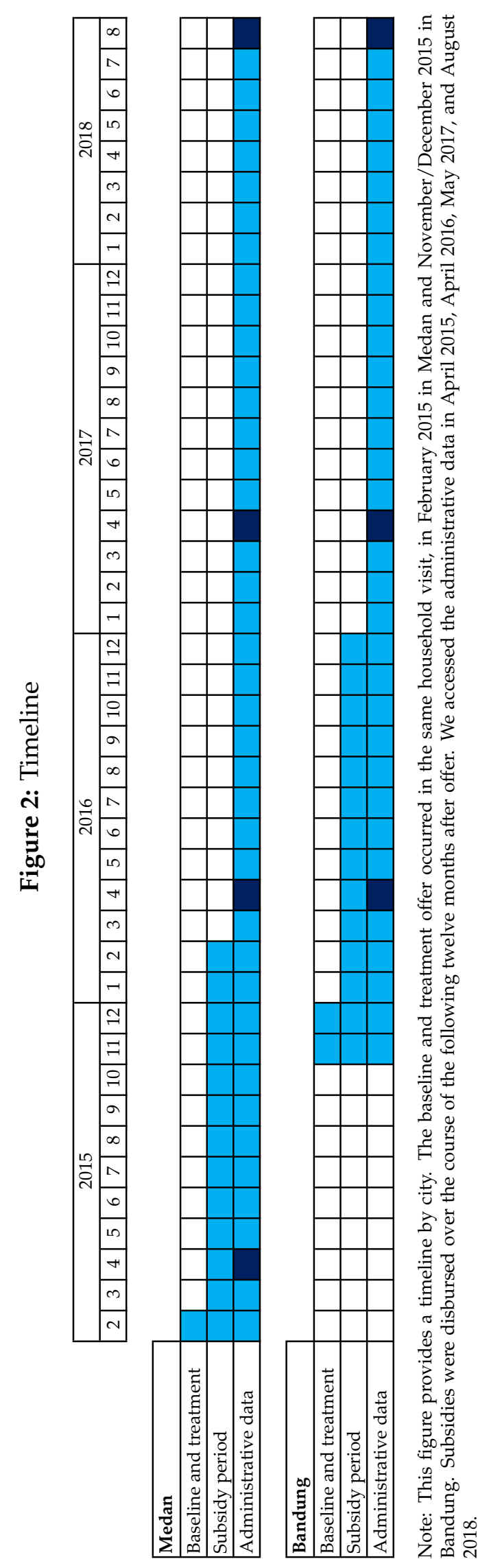




\section{Figure 3: Insurance Coverage by Month since Offer, by Subsidy Treatment}

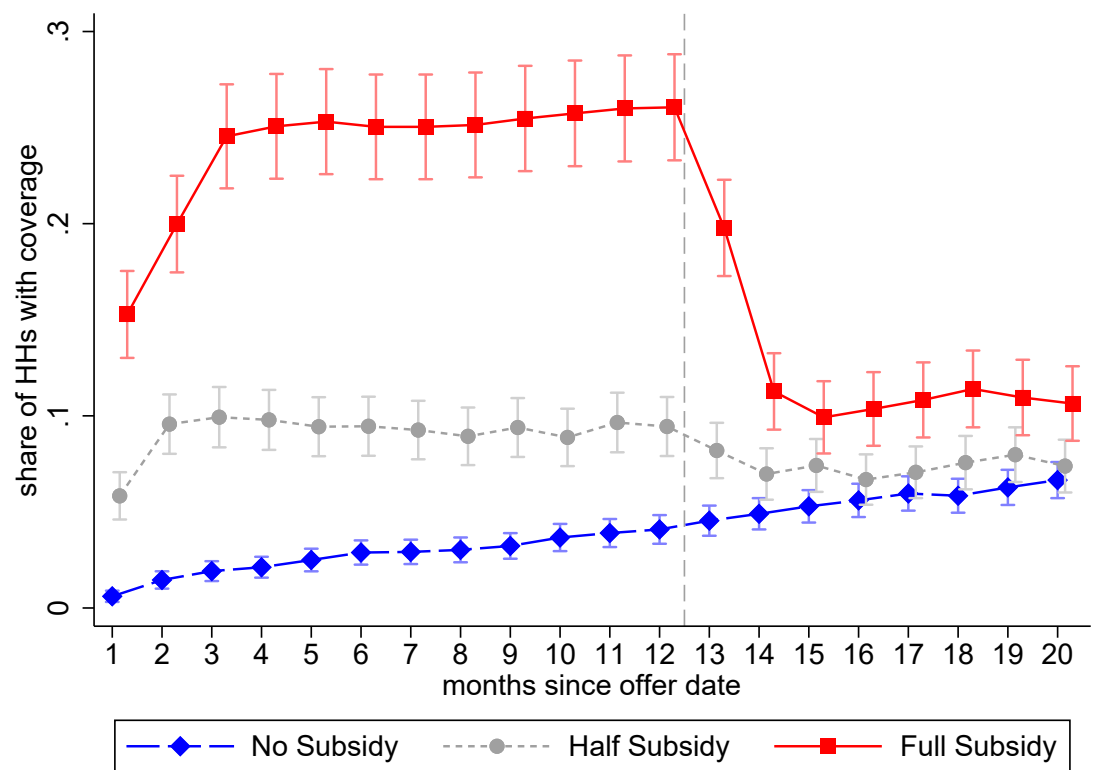

Note: This figure shows mean insurance coverage by month since the offer for households assigned to different subsidy treatments, with $95 \%$ confidence intervals for the mean. Means are weighted to reflect the intended randomization. Coverage for a household is defined as the premium having been paid in full for all its members that month. The sample size is 5996 households.

Figure 4: Distribution of Inpatient Claims, by Subsidy Treatment in Year 1 since Enrollment

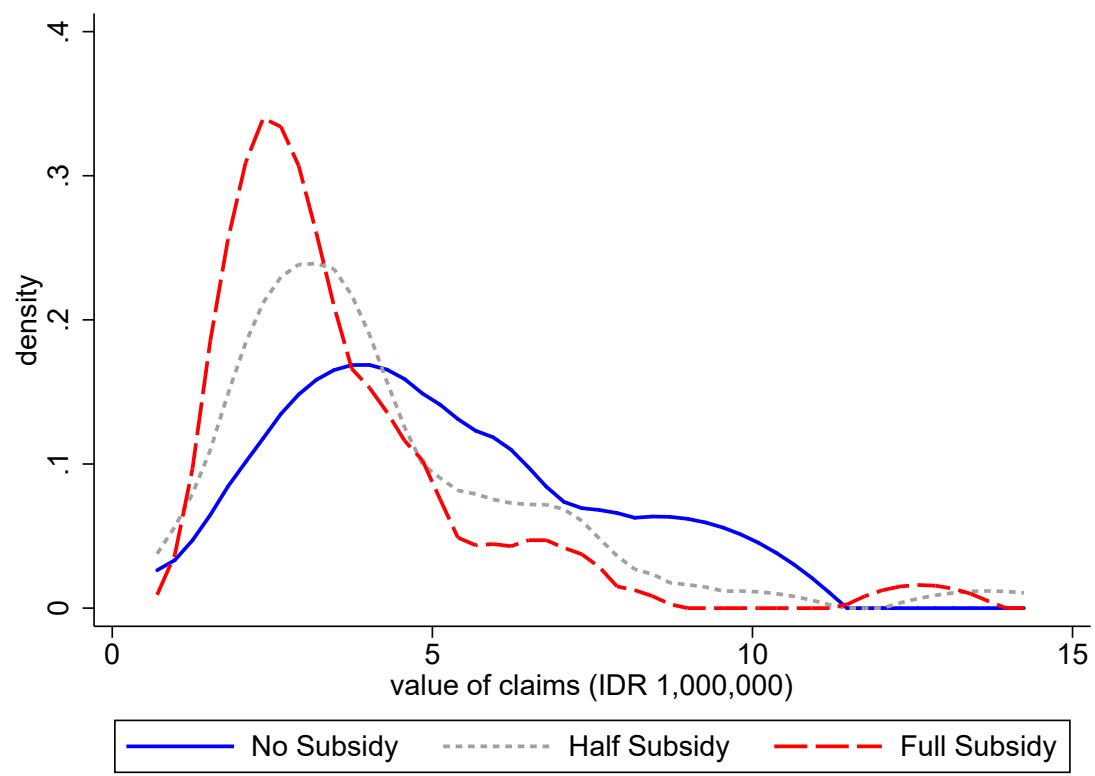

Note: This figure shows the probability distribution function of the value of inpatient claims submitted within the first twelve months since enrollment by subsidy treatment. The unit of observation is a single claim. The sample is restricted to households who enrolled within one year since offer and had coverage for at least one month over the same time period. The sample size is 3827 inpatient claims. 


\section{Figure 5: Number of Claims, by Month since Enrollment and by Subsidy Treatment}

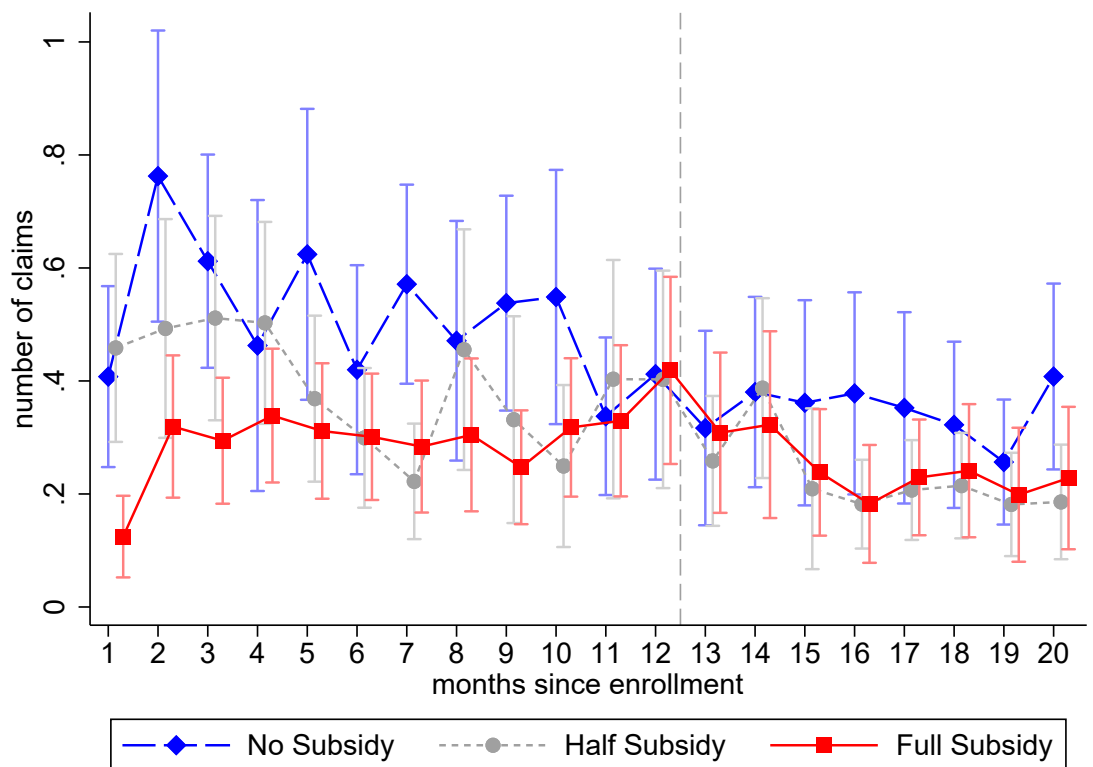

Note: The figure shows the mean number of claims in each month since enrollment with $95 \%$ confidence intervals for the mean. Means are weighted to reflect the intended randomization. The sample is restricted to households who enrolled within one year since offer and had coverage for at least one month over the same time period. The sample size is 749 households. 
Table 1: Effect of Temporary Subsidies and Assisted Internet Registration on Year 1 Enrollment

\begin{tabular}{|c|c|c|c|c|}
\hline & \multirow[b]{2}{*}{$\begin{array}{c}\text { Enrolled } \\
\text { within } 1 \text { year }\end{array}$} & \multicolumn{3}{|c|}{ Decomposition } \\
\hline & & $\begin{array}{c}\text { Attempted to } \\
\text { enroll within } \\
8 \text { weeks of } \\
\text { offer date }\end{array}$ & $\begin{array}{l}\text { Enrolled } \\
\text { within } 8 \\
\text { weeks of } \\
\text { offer date }\end{array}$ & $\begin{array}{c}\text { Enrolled } \\
\text { after } 8 \\
\text { weeks, but } \\
\text { within } 1 \text { year } \\
\text { of offer date }\end{array}$ \\
\hline & $(1)$ & $(2)$ & (3) & $(4)$ \\
\hline \multicolumn{5}{|c|}{ Panel A: Main effects } \\
\hline Full subsidy & $\begin{array}{c}0.186^{* * * *} \\
(0.020)\end{array}$ & $\begin{array}{c}0.276^{* * *} \\
(0.020)\end{array}$ & $\begin{array}{c}0.209^{* * *} \\
(0.018)\end{array}$ & $\begin{array}{c}-0.023 * * \\
(0.010)\end{array}$ \\
\hline Half subsidy & $\begin{array}{c}0.100 * * * \\
(0.014)\end{array}$ & $\begin{array}{c}0.161 * * * \\
(0.016)\end{array}$ & $\begin{array}{c}0.114 * * * \\
(0.013)\end{array}$ & $\begin{array}{l}-0.014 * \\
(0.008)\end{array}$ \\
\hline Assisted internet registration & $\begin{array}{c}0.035 * * * \\
(0.011)\end{array}$ & $\begin{array}{c}0.237 * * * \\
(0.011)\end{array}$ & $\begin{array}{c}0.043 * * * \\
(0.009)\end{array}$ & $\begin{array}{l}-0.008 \\
(0.006)\end{array}$ \\
\hline No subsidy mean & 0.086 & 0.099 & 0.030 & 0.056 \\
\hline \multicolumn{5}{|c|}{ P-value of test of hypothesis } \\
\hline Half subsidy $=$ full subsidy & 0.000 & 0.000 & 0.000 & 0.442 \\
\hline Assisted internet registration $=$ full subsidy & 0.000 & 0.107 & 0.000 & 0.266 \\
\hline \multicolumn{5}{|c|}{ Panel B: Interacted specification } \\
\hline Full subsidy and assisted internet registration & $\begin{array}{c}0.223 * * * \\
(0.025)\end{array}$ & $\begin{array}{c}0.557 * * * \\
(0.026)\end{array}$ & $\begin{array}{c}0.239 * * * \\
(0.024)\end{array}$ & $\begin{array}{l}-0.016 \\
(0.012)\end{array}$ \\
\hline Full subsidy and status quo registration & $\begin{array}{c}0.193 * * * \\
(0.027)\end{array}$ & $\begin{array}{c}0.191 * * * \\
(0.025)\end{array}$ & $\begin{array}{c}0.200^{* * *} \\
(0.024)\end{array}$ & $\begin{array}{l}-0.006 \\
(0.014)\end{array}$ \\
\hline Half subsidy and assisted internet registration & $\begin{array}{c}0.148 * * * \\
(0.025)\end{array}$ & $\begin{array}{c}0.418^{* * *} \\
(0.029)\end{array}$ & $\begin{array}{c}0.162 * * * \\
(0.023)\end{array}$ & $\begin{array}{l}-0.014 \\
(0.012)\end{array}$ \\
\hline Half subsidy and status quo registration & $\begin{array}{c}0.092 * * * \\
(0.016)\end{array}$ & $\begin{array}{c}0.099 * * * \\
(0.015)\end{array}$ & $\begin{array}{c}0.087 * * * \\
(0.013)\end{array}$ & $\begin{array}{c}0.005 \\
(0.011)\end{array}$ \\
\hline No subsidy and assisted internet registration & $\begin{array}{c}0.028 * * * \\
(0.011)\end{array}$ & $\begin{array}{c}0.179 * * * \\
(0.012)\end{array}$ & $\begin{array}{c}0.023 * * * \\
(0.007)\end{array}$ & $\begin{array}{c}0.005 \\
(0.008)\end{array}$ \\
\hline No subsidy, status quo registration mean & 0.078 & 0.018 & 0.018 & 0.060 \\
\hline
\end{tabular}

Note: This table shows the effect of subsidies and assisted internet registration on enrollment in year 1 since offer. The sample size is 5996 households. In Panel A, we regress each outcome on indicator variables for treatment assignment, an indicator variable for the randomization procedure used and an indicator variable for the study location (equation (1)). The omitted category is no subsidy for the subsidy treatments and status quo registration for the assisted internet registration treatment. The p-values reported are from a test of the difference between the half subsidy and full subsidy treatments $\left(\beta_{1}=\beta_{2}\right)$ and assisted internet registration and full subsidy treatments $\left(\beta_{1}=\beta_{3}\right)$. Panel B shows the effect of the interacted treatments on enrollment in year 1 . The omitted category is no subsidy and status quo registration treatment. All regressions are estimated by OLS and weighted to reflect the intended cross-randomization. Robust standard errors are reported in parentheses. ${ }^{* * *} \mathrm{p}<0.01,{ }^{* *} \mathrm{p}<0.05,{ }^{*} \mathrm{p}<0.1$. 
Table 2: Effect of Information on Year 1 Enrollment, by City

\begin{tabular}{|c|c|c|c|c|}
\hline & \multirow[b]{2}{*}{$\begin{array}{l}\text { Enrolled } \\
\text { within } 1 \text { year }\end{array}$} & \multicolumn{3}{|c|}{ Decomposition } \\
\hline & & $\begin{array}{c}\text { Attempted to } \\
\text { enroll within } \\
8 \text { weeks of } \\
\text { offer date }\end{array}$ & $\begin{array}{l}\text { Enrolled } \\
\text { within } 8 \\
\text { weeks of } \\
\text { offer date }\end{array}$ & $\begin{array}{c}\text { Enrolled } \\
\text { after } 8 \\
\text { weeks, but } \\
\text { within } 1 \text { year } \\
\text { of offer date }\end{array}$ \\
\hline & $(1)$ & $(2)$ & (3) & (4) \\
\hline \multicolumn{5}{|c|}{ Panel A: Medan } \\
\hline $\begin{array}{l}\text { Information on cost of treatment for heart } \\
\text { attack }\end{array}$ & $\begin{array}{c}0.029 \\
(0.029)\end{array}$ & $\begin{array}{l}-0.000 \\
(0.030)\end{array}$ & $\begin{array}{c}0.034 \\
(0.025)\end{array}$ & $\begin{array}{l}-0.005 \\
(0.016)\end{array}$ \\
\hline Observations & 1446 & 1446 & 1446 & 1446 \\
\hline No information mean & 0.190 & 0.369 & 0.131 & 0.059 \\
\hline \multicolumn{5}{|c|}{ Panel B: Bandung } \\
\hline Information on possible mandate penalties & $\begin{array}{c}0.004 \\
(0.011)\end{array}$ & $\begin{array}{c}0.015 \\
(0.012)\end{array}$ & $\begin{array}{l}-0.001 \\
(0.009)\end{array}$ & $\begin{array}{c}0.005 \\
(0.007)\end{array}$ \\
\hline Information on two weeks waiting period & $\begin{array}{c}0.011 \\
(0.011)\end{array}$ & $\begin{array}{c}0.006 \\
(0.012)\end{array}$ & $\begin{array}{c}0.009 \\
(0.009)\end{array}$ & $\begin{array}{c}0.002 \\
(0.007)\end{array}$ \\
\hline Observations & 4550 & 4550 & 4550 & 4550 \\
\hline No information mean & 0.123 & 0.188 & 0.078 & 0.045 \\
\hline
\end{tabular}

Note: This table shows the effect of the information treatments on enrollment, by city. We regress each outcome on indicator variables for treatment assignment, an indicator variable for the randomization procedure used and an indicator variable for the study location (equation (1)). The omitted category is no information for all information treatments. All regressions are estimated by OLS and weighted to reflect the intended randomization. Robust standard errors are reported in parentheses. ${ }^{* * *} \mathrm{p}<0.01,{ }^{* *} \mathrm{p}<0.05,{ }^{*} \mathrm{p}<0.1$. 


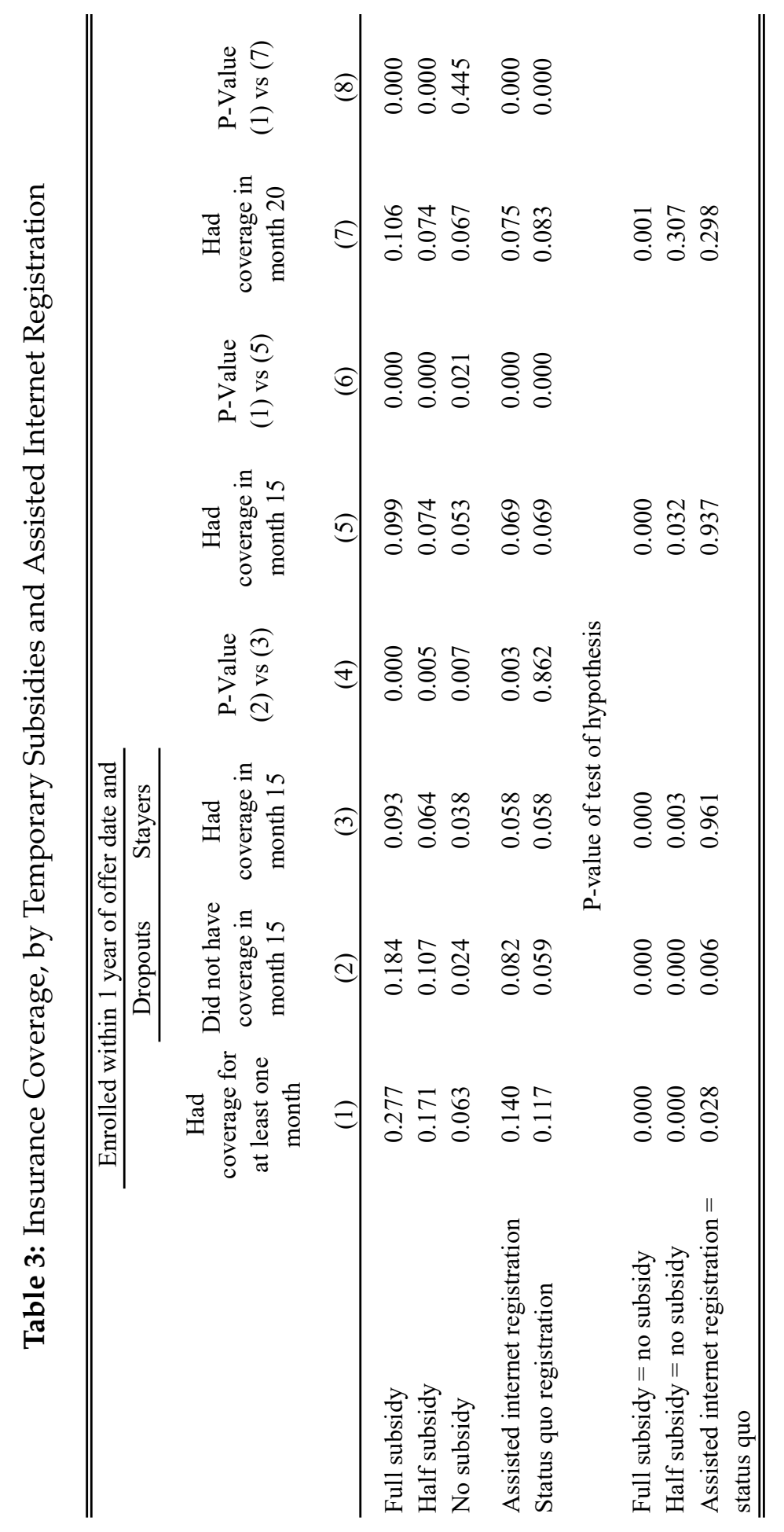

㱏 둥

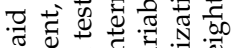

2 ह $\approx .5$

点

घ

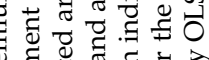

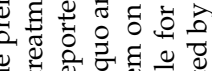

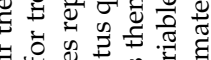

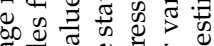

它

ठ워

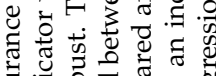

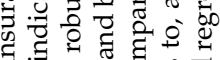

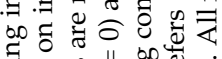

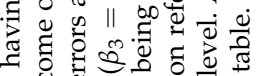

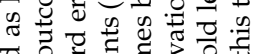

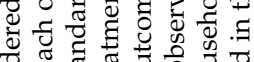

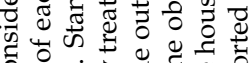

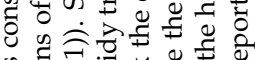

里

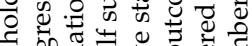

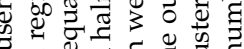

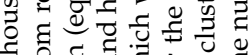

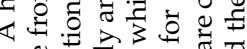

¿

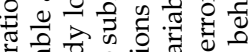

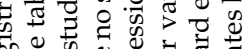

50 क

屯ै

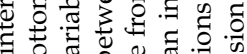

O 0

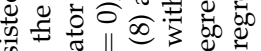

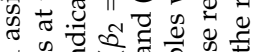

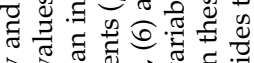

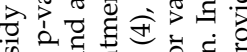

곧

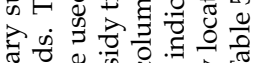

눙

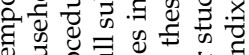

훙

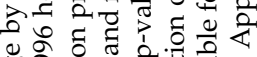

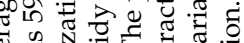

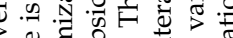

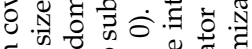

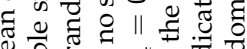

द्वे

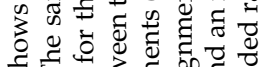

कि

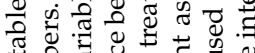

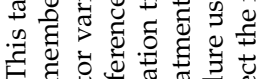

过

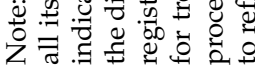




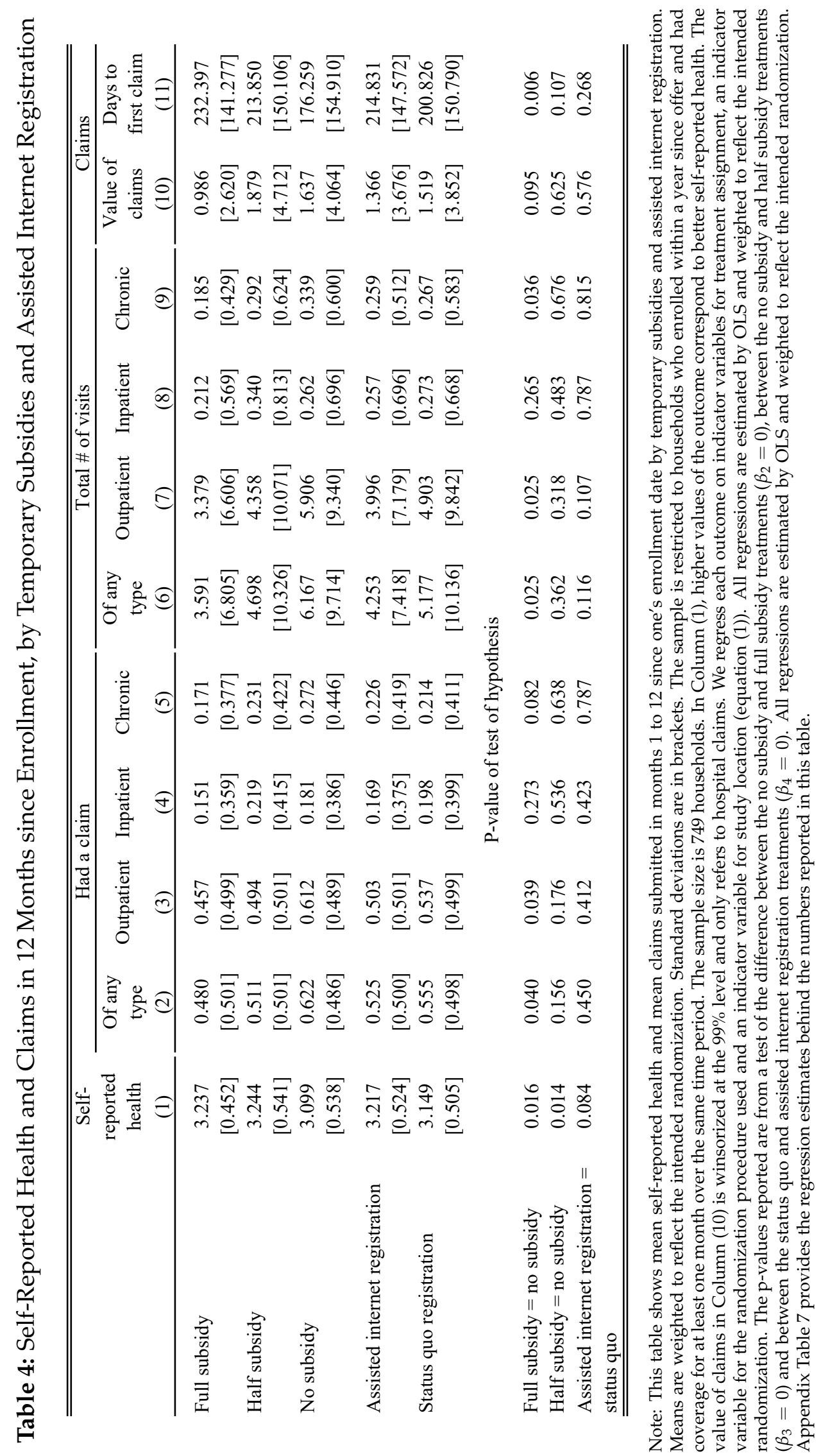




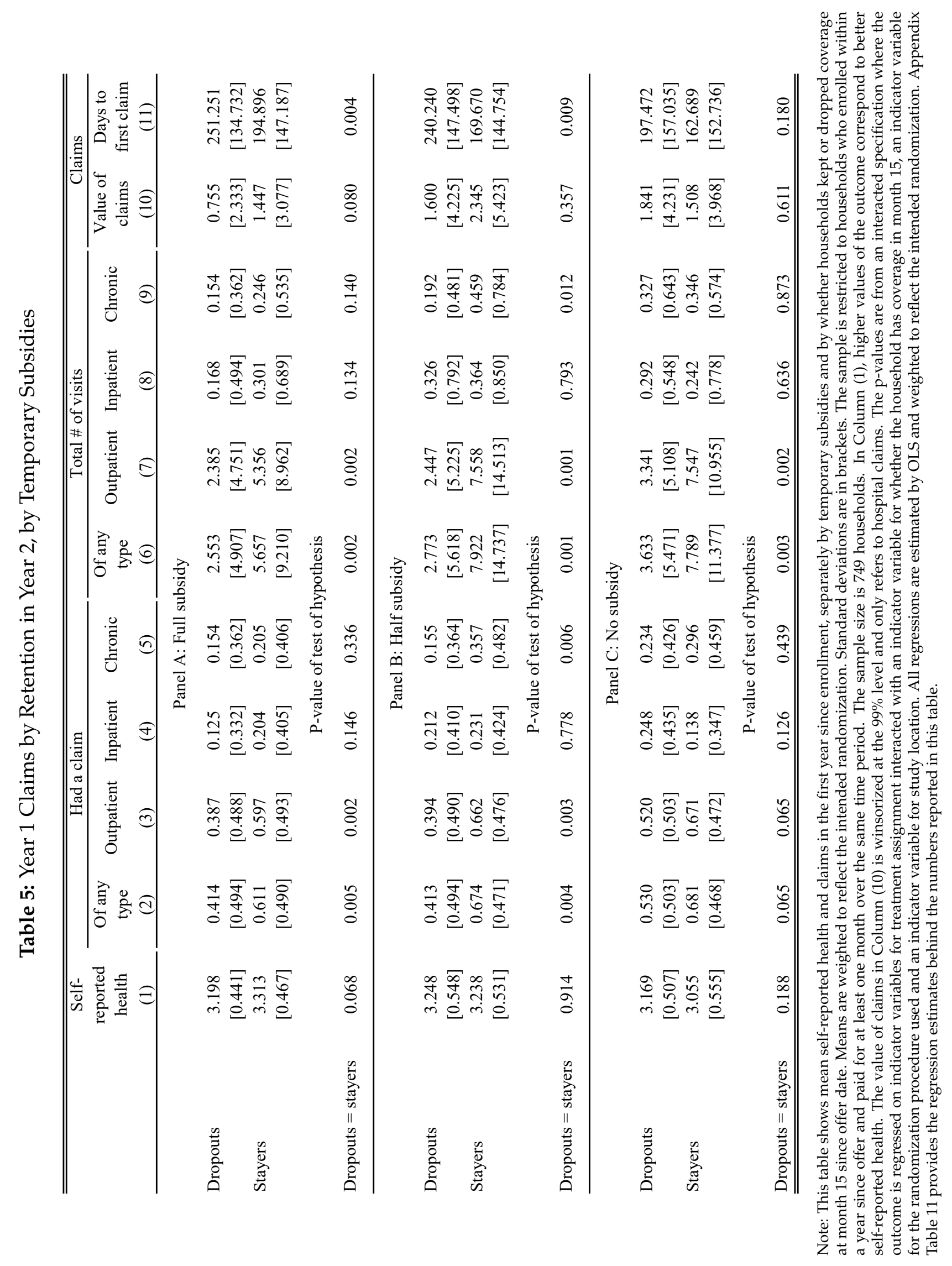




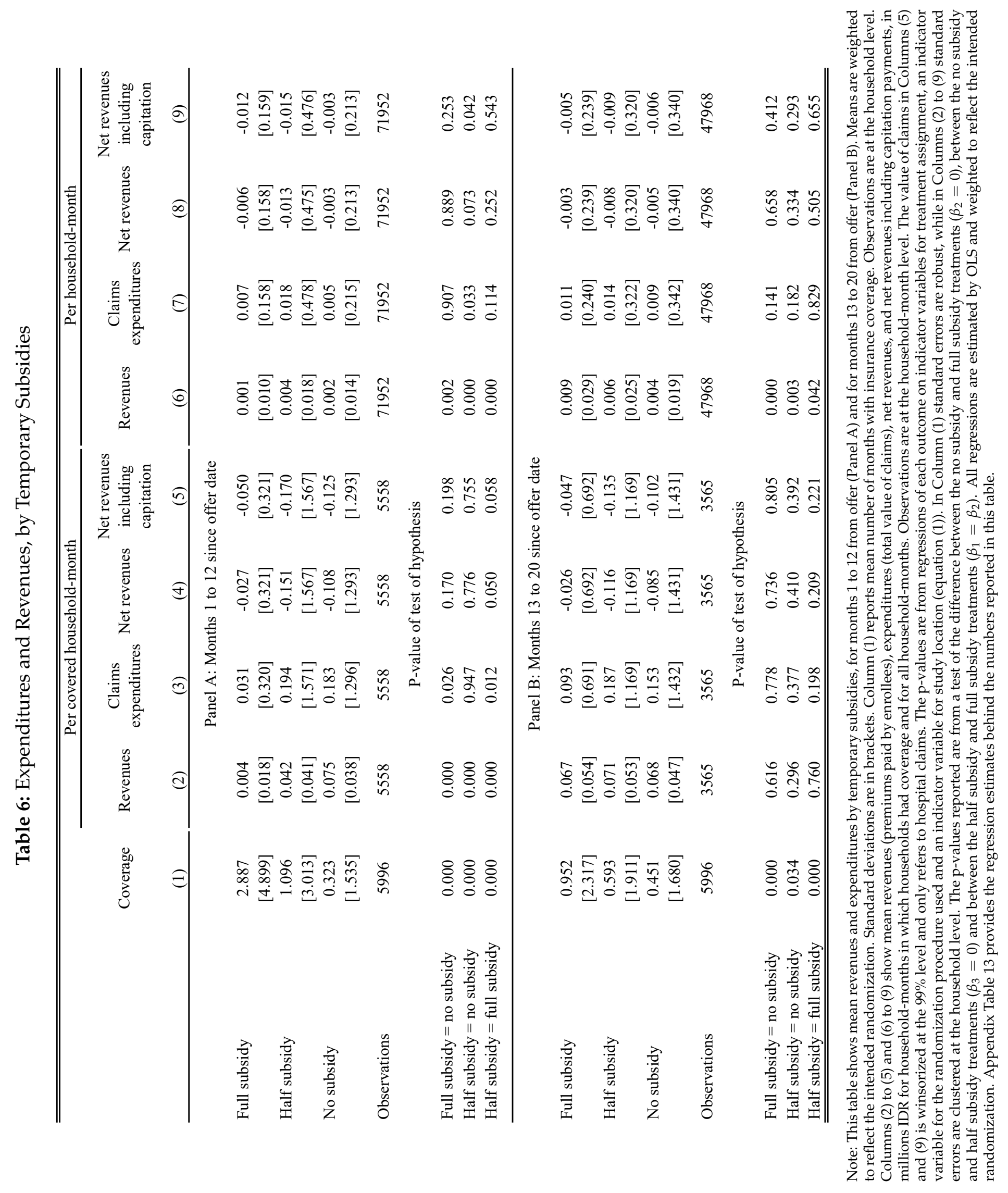

